\title{
Tuning Local Calcium Availability: Cell-Type-Specific Immobile Calcium Buffer Capacity in Hippocampal Neurons
}

\author{
Elizabeth A. Matthews, ${ }^{1}$ Susanne Schoch, ${ }^{2}$ and Dirk Dietrich ${ }^{1}$ \\ ${ }^{1}$ Department of Neurosurgery, Experimental Neurophysiology and ${ }^{2}$ Institute of Neuropathology and Department of Epileptology, University Clinic Bonn, \\ D-53105 Bonn, Germany
}

It has remained difficult to ascribe a specific functional role to immobile or fixed intracellular calcium buffers in central neurons because the amount of these buffers is unknown. Here, we explicitly isolated the fixed buffer fraction by prolonged whole-cell patch-clamp dialysis and quantified its buffering capacity in murine hippocampal slices using confocal calcium imaging and the "added-buffer" approach. In dentate granule cells, the calcium binding ratio $(\kappa)$ after complete washout of calbindin $\mathrm{D}_{28 \mathrm{k}}(\mathrm{Cb})$, $\kappa_{\text {fixed }}$, displayed a substantial value of $\sim 100$. In contrast, in CA1 oriens lacunosum moleculare (OLM) interneurons, which do not contain any known calcium-binding pro$\operatorname{tein}(s), \kappa_{\text {fixed }}$ amounted to only $\sim 30$. Based on these values, a theoretical analysis of dendritic spread of calcium after local entry showed that fixed buffers, in the absence of mobile species, decrease intracellular calcium mobility 100- and 30-fold in granule cells and OLM cells, respectively, and thereby strongly slow calcium signals. Although the large $\kappa_{\text {fixed }}$ alone strongly delays the spread of calcium in granule cells, this value optimizes the benefits of additionally expressing the mobile calcium binding protein $\mathrm{Cb}$. With such high $\kappa_{\mathrm{fixed}}$, $\mathrm{Cb}$ effectively increases the propagation velocity to levels seen in OLM cells and, contrary to expectation, does not affect the peak calcium concentration close to the source but sharpens the spatial and temporal calcium gradients. The data suggest that the amount of fixed buffers determines the temporal availability of calcium for calcium-binding partners and plays a pivotal role in setting the repertoire of cellular calcium signaling regimens.

\section{Introduction}

Calcium is a broadly active second messenger in neurons, participating in neuronal plasticity, synaptic signaling, and gene transcription (Augustine et al., 2003). An important way to achieve specificity of calcium signals is to tightly restrict the free ion in concentration, time, and space. Once calcium enters the intracellular space, the resulting spatiotemporal domain of the calcium transient is determined by the combined action of calcium diffusion, binding by buffering molecules, and removal from the cytoplasm. The resulting calcium distribution depends strongly on the exact balance between these calcium-control mechanisms (Markram et al., 1998).

Functionally, calcium buffers can be classified as fixed or mobile buffers. Although calcium ions are bound by fixed buffers, they cannot diffuse and thereby fixed buffers retard the distribution of calcium ions. When mobile buffers are added, they compete with fixed buffers for calcium ions, and those ions bound by

Received Aug. 28, 2012; revised July 12, 2013; accepted July 18, 2013.

Author contributions: E.A.M. and D.D. designed research; E.A.M. performed research; S.S. contributed unpublished reagents/analytic tools; E.A.M. and D.D. analyzed data; E.A.M., S.S., and D.D. wrote the paper.

This study was supported by German Research Foundation Grants D1853/2, D1853/3, D1853/4, and SFB TR3 D11 (D.D.), SFB 645 (S.S.), and SFB 1089 (D.D., E.A.M., and S.S.), University Clinic Bonn grants (BONFOR to E.A.M., and S.S.), and Federal Ministry of Education and Research (National Genome Research Net-Plus, "Independent Research Groups in the Neurosciences"; S.S.). We thank P. Stausberg, S. Buchholz, and J. Enders for excellent technical assistance.

The authors declare no competing financial interests.

Correspondence should be addressed to Elizabeth Matthews, Department of Neurosurgery, University Clinic Bonn, Sigmund-Freud Strasse 25, D-53105 Bonn, Germany. E-mail: emat@uni-bonn.de.

DOI:10.1523/JNEUROSCI.4118-12.2013

Copyright $\odot 2013$ the authors $\quad 0270-6474 / 13 / 3314431-15 \$ 15.00 / 0$ mobile buffers regain mobility as they diffuse together with their shuttle. In this competition, fixed calcium buffers play a pivotal and unique role in reducing the speed of spatial calcium signaling. A calcium transport equation for the apparent diffusion coefficient of calcium, $D_{\text {app }}$, in the presence of mobile and fixed buffers has been developed (Eq. 4) (Junge and McLaughlin, 1987; Zhou and Neher, 1993; Wagner and Keizer, 1994). However, to make use of this elegant and meaningful equation, it is necessary to know the endogenous buffer quantities present in the intracellular environment.

The importance of fixed calcium buffers for intracellular calcium handling is well recognized based on theoretical work (Sala and Hernández-Cruz, 1990; Nowycky and Pinter, 1993; Zhou and Neher, 1993; Kasai and Petersen, 1994; Wagner and Keizer, 1994; Zador and Koch, 1994) and on experimental observations that intracellular calcium diffusion is extremely slow in Xenopus oocytes (Allbritton et al., 1992) and in squid (Hodgkin and Keynes, 1957), Aplysia (Gabso et al., 1997), and Myxiola axoplasm (al-Baldawi and Abercrombie, 1995). Nevertheless, fixed calcium buffers and their role in dendritic calcium signaling have not received much experimental attention in the past, and their quantity in central neurons has not yet been directly determined. This may seem surprising because numerous previous studies have used calcium imaging to estimate the endogenous calcium binding capacity of neurons (Lee et al., 2000b; Kaiser et al., 2001; Sabatini et al., 2001; Goldberg et al., 2003; Evstratova et al., 2011). However, the loss of endogenous mobile buffers over the course of an experiment was not sufficiently controlled in those studies. Therefore, previous estimates are contaminated by an unknown 
amount of residual mobile buffer and represent unreliable assessments of the fixed buffering capacity of neurons. Without knowledge of the binding capacity of fixed buffers, it is difficult to predict their effect on the spatial and temporal range of calcium ions in unperturbed neurons and dendrites and the ultimate role of any additionally expressed calcium binding proteins.

In this study, we developed an experimental paradigm to isolate and quantify fixed calcium buffers in hippocampal granule cells and oriens lacunosum moleculare (OLM) interneurons. Based on this experimental quantification, we theoretically assess how fixed calcium buffers shape calcium signaling in the two types of neuron and the role of the mobile calcium binding protein in granule cells, calbindin $\mathrm{D}_{28 \mathrm{k}}(\mathrm{Cb})$.

\section{Materials and Methods}

Slice preparation. All animal experiments were performed according to national and institutional guidelines for animal welfare. The animal line used for these experiments was the calbindin $\mathrm{D}_{28 \mathrm{k}}$ knock-out line $(\mathrm{Cb}-$ KO) obtained from The Jackson Laboratory (Airaksinen et al., 1997); wild-type (WT) male and female littermates were used for most experiments except when indicated. Adult mice (P28-P48) were anesthetized and decapitated, and the brains were quickly submerged in cold oxygenated artificial CSF containing the following (in $\mathrm{mm}$ ): $87 \mathrm{NaCl}, 2.5 \mathrm{KCl}$, $1.25 \mathrm{NaH}_{2} \mathrm{PO}_{4}, 7 \mathrm{MgCl}_{2}, 0.5 \mathrm{CaCl}_{2}, 25 \mathrm{NaHCO}_{3}, 25$ glucose, and 75 sucrose, $\mathrm{pH}$ 7.3. Horizontal slices $(300 \mu \mathrm{m})$ were made from the ventral hippocampus. Slices were removed from the chilled solution and incubated at $35^{\circ} \mathrm{C}$ for $30 \mathrm{~min}$ in the same solution. After the incubation period, slices were held at room temperature in a bubbled $\left(95 \% \mathrm{O}_{2} / 5 \%\right.$ $\mathrm{CO}_{2}$ ) solution containing the following (in $\mathrm{mm}$ ): $124 \mathrm{NaCl}, 3 \mathrm{KCl}, 1.25$ $\mathrm{NaH}_{2} \mathrm{PO}_{4}, 2 \mathrm{MgCl}_{2}, 2 \mathrm{CaCl}_{2}, 26 \mathrm{NaHCO}_{3}$, and 10 glucose, $\mathrm{pH}$ 7.3. This solution was used for all subsequent electrophysiology and imaging experiments.

Electrophysiology and confocal calcium imaging. Patch pipettes with a resistance between 4 and $6 \mathrm{M} \Omega$ were filled with internal solution containing the following (in $\mathrm{mM}$ ): $130 \mathrm{~K}$-gluconate, $0.5 \mathrm{MgCl}_{2}, 4 \mathrm{NaCl}, 5$ $\mathrm{KCl}, 4 \mathrm{Na}_{2}-\mathrm{ATP}$, and 10 HEPES, pH adjusted to 7.35 with $\mathrm{KOH}$. A $4 \mathrm{mM}$ stock of Oregon Green BAPTA-6F, low-affinity form (OGB-6F; Invitrogen) was made in the internal solution and was diluted to the desired working concentration daily. For the interneuron recordings, tetramethylrhodamine-biocytin (TMR-biocytin; Invitrogen) was added to the internal solution at $100 \mu \mathrm{M}$ for later morphological identification of the recorded cells. In the experiments to verify the removal of parvalbumin (PV) from the recorded interneurons, $0.1 \%$ Lucifer yellow (Sigma-Aldrich) was added to the pipette solution.

Hippocampal slices were placed in a submerged chamber on the stage of an LSM5 Pascal confocal microscope (Axioskop; Carl Zeiss) for recording and imaging. Dentate granule cells and CA1 interneurons were visually selected and patched using an NPI current-clamp amplifier (ELC-01X) and TIDA (HEKA) acquisition software. Electrical signals were sampled at $30 \mathrm{kHz}$ and low-pass filtered at $10 \mathrm{kHz}$, and the liquid junction potential was corrected by setting the amplifier offset to $-10 \mathrm{mV}$ before seal formation. Pipette capacitance and bridge balancing was performed within the first minutes of recording and checked for stability periodically throughout the recording and imaging experiment. Calcium transients were generated by a $0.5 \mathrm{~ms}$ current injection at the soma $(0.8-1.5 \mathrm{nA})$. Line scans were made perpendicular to the primary dendrite at an average of $10.8 \pm 1.2 \mu \mathrm{m}$ from the edge of the soma (granule cells) or across a dendrite at an average distance of $10.9 \pm 0.9 \mu \mathrm{m}$ from the edge of the soma (interneurons). Excitation wavelength was $488 \mathrm{~nm}$; emitted fluorescence was collected with a Carl Zeiss $63 \times, 1.0$ numerical aperture (NA) objective. OGB-6F fluorescence was collected with a bandpass filter at 505-600 $\mathrm{nm}$. When TMR-biocytin was present in the pipette, OGB-6F fluorescence was bandpass filtered at 500-550.

Cells along the inner granule cell layer were avoided, because the immature granule cells found here do not express $\mathrm{Cb}$ (Müller et al., 2005). The average resting potential of the granule cells included in the study was $-74.8 \pm 0.1 \mathrm{mV}$; the average input resistance was $213 \pm$ $1 \mathrm{M} \Omega$ [WT, $n=24$; Cb-KO, $n=22$; no difference between WT and Cb-KO groups $(p>0.1)$, data pooled]. Interneurons were selected based on their size, soma orientation parallel to the CA1 pyramidal layer, and location in the outer third of the stratum oriens. Interneurons were given a $1 \mathrm{~s}$ current injection protocol to characterize sag and action potential firing ( -150 to $200 \mathrm{pA}, 50 \mathrm{pA}$ steps). The average resting potential of the OLM cells included in the study $(n=14)$ was $-63.4 \pm 0.2 \mathrm{mV}$, the average input resistance was $383 \pm 8 \mathrm{M} \Omega$, and the average firing frequency to a $200 \mathrm{pA}$ current injection was $41.4 \pm$ $0.8 \mathrm{~Hz}$. All interneurons recorded for this study were filled with biocytin during the course of the experiment, and the tissue was later fixed and processed to identify the axon. In 12 of 14 cells, the axon was identified and extended from the cell body in the stratum oriens through the stratum pyramidal into the stratum lacunosum moleculare. The axons of the two remaining cells were only partially recovered; however, their electrophysiological properties were strongly indicative of OLM identity, and they were included in the analysis set (sag relative to steady state, $-20.6 \pm 1.4 \mathrm{mV}$; absolute sag, $-132.0 \pm$ $20.5 \mathrm{mV}$; firing frequency at $200 \mathrm{pA}, 36.5 \pm 0.5 \mathrm{~Hz}$ ).

Immunohistochemistry and cell recovery. Slices with cells to be reconstructed were fixed overnight in $0.8 \%$ paraformaldehyde, rinsed, and stored in $0.1 \mathrm{M}$ Tris-buffered saline (TBS) for resectioning. Slices were embedded in $5 \%$ agar, sliced at $75 \mu \mathrm{m}$ on a vibratome (Leica), and then returned to TBS. For confirmation of the axonal arbors of the interneurons, the sections were incubated overnight in Rhodamine Red-X Streptavidin (1:10,000; Jackson ImmunoResearch), Niss green (1:10,000; Invitrogen), and $0.2 \%$ Triton X-100 (SigmaAldrich). All sections were then washed in TBS, mounted on a slide, and coverslipped. Interneuron axonal morphology was visually confirmed on a fluorescent wide-field Nikon TS-100 with a $40 \times, 0.75 \mathrm{NA}$ coverslip corrected objective.

Slices that were used to verify the absence of PV after the long-duration whole-cell OLM recordings were fixed and embedded as described above but resectioned at $50 \mu \mathrm{m}$ to improve antibody penetration of the tissue. Sections containing the soma of the recorded cells were incubated overnight with rabbit $\alpha$-PV (1:50,000; Swant) with $0.2 \%$ Triton X-100 and goat $\alpha$-rabbit Rhodamine Red-X (1:30,000; Jackson ImmunoResearch). The labeled cells were imaged using the Carl Zeiss confocal microscope described above with a slide holder replacing the recording chamber and a $40 \times, 1.1$ NA water-immersion objective with correction ring.

Image analyses. Immunohistochemical images were overlaid using NIH ImageJ, and OLM morphology was traced with the NeuronJ plugin and aligned in Photoshop (Adobe Systems). IgorPro 6.1 (Wavemetrics) was used to analyze calcium imaging data. Background fluorescence was measured from either side of the dendrite and subtracted. The amplitude of action-potential-evoked increases in fluorescence was calculated as the percentage increase over the resting baseline fluorescence, $\Delta F / F(\%)$. Fluorescence decay was fitted with a single exponential using the standard fitting algorithm of IgorPro.

Analysis of the longitudinal dendritic scans to verify spatial homogeneity of calcium elevations was done with $100 \mu \mathrm{M}$ OGB-6F. After background subtraction, scanned lines were cut to $14 \mu \mathrm{m}$ (granule cells) or $25 \mu \mathrm{m}$ (OLM) and care was taken that the entire segment lay within the dendrite. The image was then normalized on the prestimulus fluorescent spatial profile. We used a single line scan at the time of peak to detect any hotspots of calcium entry along the length of the dendrite. To improve the signal to noise ratio, the line profile was box smoothed (8-11 pixels, $0.08-0.1 \mu \mathrm{m} / \mathrm{pixel})$ and resampled to generate $1 \mu \mathrm{m}$ bins. We treat all spatial inhomogeneities of fluorescence in this profile as inhomogeneities of calcium entry to obtain an upper estimate of diffusional contamination of our measurements of calcium extrusion time constants. The differences of the $\Delta F / F$ value between each binned pixel and its neighboring pixels were summed $\left(\operatorname{Bin}_{i}-\operatorname{Bin}_{i-1}+\operatorname{Bin}_{i}-\operatorname{Bin}_{i+1}\right)$; each of these sums of the differences was normalized on the $\Delta F / F$ value of the central bin. By Fick's law of diffusion, these normalized differences are proportional to the instantaneous relative net calcium flux out of the central bin. If there is only random noise in the system, the mean flux out of the bins 
should be zero and the amount of noise determines the standard deviation. The normalized differences (\%) for all bins of all dendritic segments were plotted as a histogram for each cell type. The histograms were well fit by a Gaussian centered at zero, with a width of $35 \%$ flux (granule cells) and 16\% flux (OLM). A dendritic hotspot of calcium entry would appear as additional peaks in the histogram, but no additional peaks were observed. We cannot fully exclude that peaks $<35 \%$ are hidden in the center of the histogram. However, even an initial normalized difference of $35 \%$ in calcium entry (between neighboring bins) would at most result in only an $\sim 12 \%$ change in calcium concentration in each bin (35\%/three bins) after complete diffusional equilibration. A change in $\Delta F / F$ of $12 \%$ attributable to diffusion along the dendrite is small compared with a drop of $\sim 63 \%$ in one decay time constant. This indicates that our measures of the time constant primarily reflect the extrusion of calcium and not diffusion of calcium along the dendrite.

Theory of buffered calcium diffusion. We used several common simplifying assumptions about calcium reaction and diffusion to derive $\kappa_{\text {fixed }}$ and to estimate the impact of fixed buffers on calcium spread in dendrites, analytically: linearity and the rapid buffer approximation. The assumption of the linearity of calcium binding in the system with respect to free calcium is likely correct because both the chosen calcium indicator and endogenous fixed buffers have a low calcium affinity $\left(K_{\mathrm{d}}=3.1 \mu \mathrm{M}\right.$ and $K_{d} \gg 3 \mu \mathrm{M}$ ) (Allbritton et al., 1992; Zhou and Neher, 1993; Xu et al., 1997). Furthermore, free calcium in response to three action potentials was probably $<500 \mathrm{~nm}$ in both granule cells and OLM interneurons even in the absence of dye $\left(F_{\max } / F_{\min }=12.0, K_{\mathrm{d}}=2.7 \mu \mathrm{M}\right.$ determined in vitro, $\mathrm{Ca}^{2+}{ }_{\text {rest }}=100 \mathrm{nM}$, determined by numerically solving the differential equations given by the single-compartment model). However, the requirement of linearity may not be fulfilled during the early recording period in granule cells when a substantial fraction of $\mathrm{Cb}$ is still present. Because $\mathrm{Cb}$ has a relatively high calcium affinity ( $\sim 700 \mathrm{nM}$; Berggård et al., 2002), it will only respond sublinearly to such calcium excursions (Jackson and Redman, 2003). For this reason, and because a fraction of $\mathrm{Cb}$ may have been lost during the early recording period, the endogenous calcium binding ratio, $\kappa_{\text {endo }}$, calculated during the early period underestimates the full calcium binding ratio of granule cells.

The calcium binding ratio of a buffer at resting calcium concentration was calculated according to Neher and Augustine (1992):

$$
\kappa=\frac{\partial\left[\text { Buffer }-\mathrm{Ca}^{2+}\right]}{\partial\left[\mathrm{Ca}^{2+}\right]_{\text {rest }}}=\frac{[\text { Buffer }]_{\text {total }} K_{\mathrm{d}}}{\left(\left[\mathrm{Ca}^{2+}\right]_{\text {rest }}+K_{\mathrm{d}}\right)^{2}} .
$$

The endogenous calcium binding ratio, $\kappa_{\text {endo }}$, can be extrapolated from the decay $(\tau)$ of a calcium transient by varying the exogenous calcium binding ratio, $\kappa_{\text {dye }}$, contributed by the indicator. This linear relationship is described by the following:

$$
\tau=\frac{1}{\gamma} \kappa_{\text {dye }}+\frac{1+\kappa_{\text {endo }}}{\gamma}
$$

where $\gamma$ is the extrusion rate. Strictly speaking, in our case, $\kappa_{\text {endo }}$ represents the incremental endogenous calcium binding ratio (Helmchen et al., 1996), because action potentials do not produce an infinitesimal calcium increase (required by Eq. 1).

Additionally, $\kappa_{\text {endo }}$ can be calculated from the inverse of the actionpotential-induced change in calcium concentration according to the following:

$$
\frac{1}{\Delta\left[\mathrm{Ca}^{2+}\right]_{\text {free }}}=\frac{1}{\Delta\left[\mathrm{Ca}^{2+}\right]_{\text {total }}} \kappa_{\text {dye }}+\frac{1+\kappa_{\text {endo }}}{\Delta\left[\mathrm{Ca}^{2+}\right]_{\text {total }}} .
$$

Because we were careful to remain within the linear range of the calcium indicator (Fig. 1 and above), $(\Delta F / F)^{-1}$ will be proportional to $\frac{1}{\Delta\left[\mathrm{Ca}^{2+}\right]_{\text {free }}}$ and can be used to infer $\kappa_{\text {endo }}$ in a second and independent way. The value of $\kappa_{\text {dye }}$ was calculated from the concentration of OGB-6F in the pipette using Equation 1, a resting calcium concentration of $0.1 \mu \mathrm{M}$ and the manufacturer provided $K_{\mathrm{d}}=3.1 \mu \mathrm{M}$.
All values reported in this study are in the form mean \pm SEM. Error propagation rules were used to compute the error of the extrapolated values (e.g., $D_{\text {app }}$ ).

Apparent diffusion coefficient. The apparent diffusion coefficient of calcium, $D_{\text {app }}$, in the presence of a mixed buffer population is as follows:

$$
D_{\text {app }}=D_{\mathrm{Ca}^{2}+} \frac{\left(1+\frac{D_{\mathrm{m}}}{D_{\mathrm{Ca}^{2+}}} \kappa_{\mathrm{m}}\right)}{\left(1+\kappa_{\mathrm{m}}+\kappa_{\mathrm{f}}\right)},
$$

where $D_{\mathrm{Ca} 2+}$ is the diffusion coefficient of free calcium in the cytosol, $D_{\mathrm{m}}$ is the diffusion coefficient of mobile buffers, and $\kappa_{\mathrm{m}}$ and $\kappa_{\mathrm{f}}$ are the calcium binding ratios of the mobile and fixed buffers, respectively (Junge and McLaughlin, 1987; Zhou and Neher, 1993; Wagner and Keizer, 1994).

Measuring the calcium binding ratio of the pipette solution. The calcium binding capacity of the internal solution is primarily determined by the calcium indicator dye (OGB-6F) but may be increased by other constituents of the solution. We determined the contribution of other constituents in vitro by adding known amounts of total calcium and inferring the increase in bound calcium from the increase in free calcium concentration (for each titration step: $\Delta \mathrm{Ca}_{\text {bound }}^{2+}=\mathrm{Ca}_{\text {added in total }}^{2+}-\mathrm{Ca}_{\text {free }}^{2+}$ ) measured as an increased emission by OGB-6F with a spectrofluorometer (QuantaMaster-40; PTI). Only ATP, but not K-gluconate, $\mathrm{MgCl}_{2}$, HEPES, or $\mathrm{KCl}$, displayed a measurable calcium binding ratio at the concentrations used for the internal solution. The following solution was used for the calcium binding ratio assay ("assay solution"): $100 \mathrm{~mm} \mathrm{KCl,}$ $10 \mathrm{~mm}$ HEPES, $4 \mu \mathrm{M} \mathrm{MgCl}$, and $8.6 \mu \mathrm{M}$ OGB-6F, pH 7.3. We used $4 \mu \mathrm{M}$ $\mathrm{MgCl}_{2}$, because this is the predicted free magnesium concentration of our internal solution containing $0.5 \mathrm{~mm} \mathrm{MgCl}_{2}$ and $4 \mathrm{mM} \mathrm{Na}_{2} \mathrm{ATP}$. We determined the calcium affinity of OGB-6F, as well as $F_{\min }$ and $F_{\max }$, in this assay solution in separate experiments (see below). The binding ratio of the assay solution was $1.2 \pm 0.1(n=4)$ as determined from the slope of the plot of $\mathrm{Ca}_{\text {bound }}^{2+}$ versus $\mathrm{Ca}_{\text {free }}^{2+}$ with free calcium in the range of $1-3 \mu \mathrm{M}$, which is in good agreement with the theoretical $\kappa$ value according to Equation $1\left(K_{\mathrm{d}}\right.$ of the manufacturer and $\left.1 \mu \mathrm{M}\left[\mathrm{Ca}^{2+}{ }_{\text {rest }}\right]\right)$. When we increased $\mathrm{MgCl}_{2}$ to $0.5 \mathrm{~mm}$ and added $4 \mathrm{mM} \mathrm{Na}_{2} \mathrm{ATP}$ to the assay solution the slope of the plot of $\mathrm{Ca}_{\text {bound }}^{2+}$ versus $\mathrm{Ca}_{\text {free }}^{2+}$ strongly increased to $43 \pm 1.4(n=4)$ and was constant up to $\sim 6 \mu \mathrm{M}$ free calcium. The relevance of this finding is discussed below.

Determining the fluorescent properties of OGB- $6 F$. For the calibration experiments described here and for determination of the calcium binding ratio, we used the following settings of the spectrofluorometer: emission wave length $488 \mathrm{~nm} / 1 \mathrm{~nm}$ slit width; emission measured at $525 \mathrm{~nm} / 2$ $\mathrm{nm}$ slit width; $10 \mathrm{~s}$ integration time. The maximum and minimum fluorescent values of the dye $\left(F_{\max }, F_{\min }\right)$ were measured in the assay solution with $10 \mathrm{~mm} \mathrm{CaCl}_{2}$ or $150 \mu \mathrm{M}$ EDTA, respectively. To determine the $K_{\mathrm{d}}$ value of OGB-6F, we first carefully added calcium to the assay solution until the fluorescent reading equaled $\left(F_{\max }+F_{\min }\right) / 2$, implying that the free calcium concentration then equals the $K_{\mathrm{d}}$ value of OGB-6F. We then used an EDTA titration to determine the total calcium concentration contained in this solution and calculated the affinity of OGB-6F in the assay solution as $K_{\mathrm{d}}=\mathrm{Ca}_{\text {free }}^{2+}=\mathrm{Ca}_{\text {total }}^{2+}-\mathrm{Ca}_{\text {bound }}^{2+}=\mathrm{Ca}_{\text {total }}^{2+}-0.5 \times$ OGB- $6 \mathrm{~F}_{\text {total }}=3.6 \pm 0.3 \mu \mathrm{M}(n=7)$.

The finding that ATP contributes a $\kappa$ value of $\sim 40$ to the calcium binding ratio of our pipette solution raises the question whether this value has to be added to $\kappa_{\text {dye }}$ (Eqs. 2, 3). It is less clear for ATP and magnesium than for OGB-6F whether the intracellular concentration during an experiment can be controlled by the pipette solution. ATP is metabolized for energy production, and, depending on the energy consumption of the cell during the recording, ATP may be eliminated at a rate such that the concentration inside the pipette $(4 \mathrm{~mm})$ is never achieved intracellularly. Furthermore, ATP also hydrolyzes spontaneously at a certain rate and the concentration inside the pipette may be $<4 \mathrm{~mm}$ during an experimental session. The intracellular magnesium level is not only heavily buffered by binding to nucleotides, among them ATP, and many intracellular proteins but is also important for the activity of a number of ion channels, receptors, and enzymes. Therefore, it is likely that there is an intracellular regulation mechanism keeping the 
A

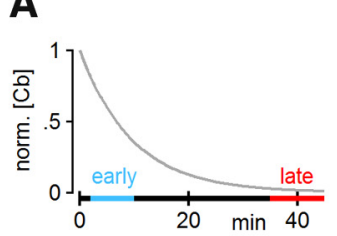

B
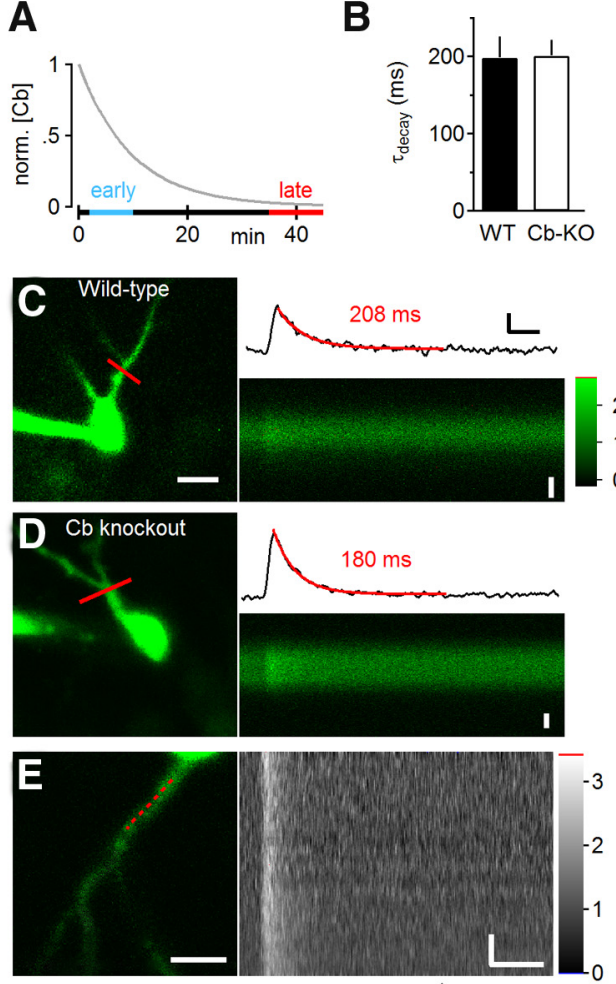

F
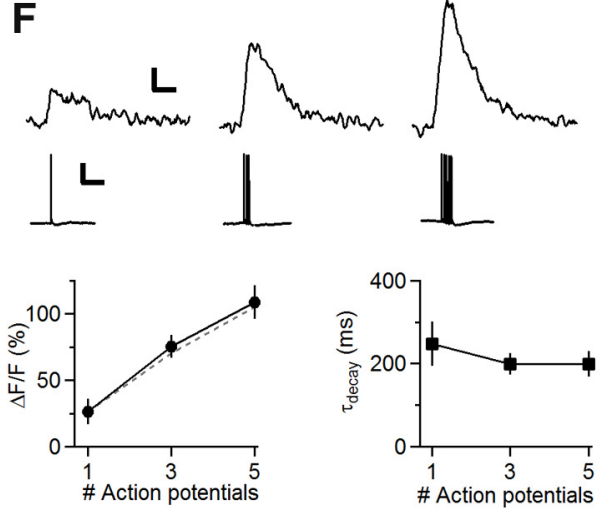

Figure 1. Long-duration whole-cell recording functionally removes $C b$. A, Previous work using immunohistochemistry has shown that Cb washes out with a time constant of $\sim 10 \mathrm{~min}$ (Müller et al., 2005). This time course was used to define the early and late recording intervals in this study (blue and red bars). $\boldsymbol{B}$, The average decay time constant of action-potential-evoked calcium transients is the same in WT and Cb-KO granule cells. $\boldsymbol{C}, \boldsymbol{D}$, Example frame scans (left, $10 \mu \mathrm{m}$ ) and repetitive line scans (right, $1 \mu \mathrm{m}$, time is on $x$-axis and runs from left to right, same $x$-scaling as transient) obtained with a confocal laser microscope from cells in WT and Cb-KO mice. The red line in the left panel shows the location of the line scan. The black trace represents the average brightness of indicator fluorescence of each scanned line over time, the calcium transient. Calibration: $250 \mathrm{~ms}, 0.2 \Delta F / F$. The best monoexponential fit (red line) and decay time constant (in red) are shown. $\boldsymbol{E}$, Action-potential-evoked calcium signals are global within proximal dendritic segments. Example frame scan (left, $10 \mu \mathrm{m}$ ) of a proximal granule cell dendrite. Red dashed line indicates where the line was scanned along a segment (14 $\mu \mathrm{m})$ of primary granule cell dendrite. Right, The resulting line scans were background subtracted and normalized on the prestimulus baseline ( $200 \mathrm{~ms}, 2 \mu \mathrm{m})$. Note that no hotspots in fluorescence were found in the four granule cells and four OLM cells (data not shown) examined. Additional analysis of the spatial homogeneity of calcium entry evoked by action potentials is described in Materials and Methods. $\boldsymbol{F}$, The low-affinity calcium indicator 0GB-6F (100 $\mu \mathrm{m})$ quasi-linearly reports calcium entry. Top row, Top traces, Calcium transients ( $200 \mathrm{~ms}, 0.2 \Delta F / F)$ acquired as shown in $C$ and $\boldsymbol{D}$ in response to 1,3 , and 5 action potentials ( $50 \mathrm{~Hz}$, bottom row, $200 \mathrm{~ms}, 30 \mathrm{mV}$ ). Bottom graphs, Calcium signals show no signs of sublinearity of OGB-6F. Summary of experiments indicate that the relative fluorescence increases as expected with the number of action potentials (left) and that there is no increase in the decay time constant when higher calcium levels are reached in response to multiple action potentials (right). The dashed line in the left graph indicates the expected increase in $\Delta F / F$ for a $50 \mathrm{~Hz}$ train of action potentials assuming the exponential fluorescent decay is the same for each successive action potential as for the first action potential. intracellular magnesium concentration constant. It has been estimated that the free intracellular magnesium level is $\sim 500 \mu \mathrm{M}$ (Sinha et al., 1997), i.e., two orders of magnitude larger than the free magnesium concentration in our pipette solution. If the intracellular regulation mechanism is able to at least partially compensate for the dilution of intracellular magnesium concentration by our pipette solution, the resulting magnesium level during an experiment may far exceed $4 \mu \mathrm{m}$ and, as a consequence, will reduce the ATP available for calcium buffering. Together, the intracellular $\kappa$ value of ATP during a patch-clamp experiment may well be much smaller than the one we have determined in our in vitro assay relying on the nominal concentrations of ATP and magnesium in our pipette solution. To experimentally explore whether or not the addition of ATP adds to the $\kappa$ value of our pipette solution, we compared the calcium decay time constant between cells recorded with and without ATP. For this experiment, we chose OLM cells because they have a low level of endogenous calcium buffers, and their decay time constant would therefore be most sensitive to changes of the $\kappa$ value of the pipette solution. However, there was no difference in the decay time constants between OLM cells recorded with ATP and cells recorded without ATP in the pipette $\left(100 \mu \mathrm{M}\right.$ OGB- $6 \mathrm{~F}, \tau_{\mathrm{ATP}}=240 \pm 42 \mathrm{~ms}, \tau_{\mathrm{No}}$ ATP $=$ $262 \pm 26 \mathrm{~ms}$; not significant). This strongly suggests that the added calcium binding ratio in both the presence and absence of ATP are the same or very similar. Thus, we believe it is justified to quantify the $\kappa$ value of the internal solution solely based on $\kappa_{\text {dye }}$, as it was performed in previous studies (Neher and Augustine, 1992; Helmchen et al., 1996; Maravall et al., 2000; Aponte et al., 2008; Evstratova et al., 2011).

Simulation of calcium diffusion, buffering, and extrusion. We simulated buffered calcium diffusion in a 1D $300 \mu \mathrm{m}$ tube using The Calcium Calculator written by Victor Matveev (New Jersey Institute of Technology, Newark, NJ). Calcium entry was spatially and temporally homogenous in the center of the tube over a region of $300 \mathrm{~nm}$ for $0.8 \mathrm{~ms}$. We used 4000 grid points and a stretch factor of 1.05 outside the region of $\pm 1 \mu \mathrm{m}$ from the center. Background calcium concentration was $100 \mathrm{~nm}$, and the diffusion coefficient for unbound calcium was $0.22 \mu \mathrm{m}^{2} / \mathrm{ms}$. Calcium extrusion was modeled as a spatially homogeneous linear process driven by the calcium concentration increase above the resting concentration.

To simulate granule cells containing only fixed buffer, we used the following parameters: fixed buffer concentration of $5000 \mu \mathrm{M}, K_{\mathrm{d}}=$ $50 \mu \mathrm{M}, k_{\mathrm{on}}=0.4(\mathrm{~ms} \mu \mathrm{M})^{-1}$, and diffusion coefficient of 0 ; extrusion rate, $0.85 \mathrm{~ms}^{-1}$; calcium current amplitude, $21.45 \mathrm{pA}$. With this set of parameters, we achieved a calcium increase of $\sim 600 \mathrm{~nm}$ and a time constant of $\sim 130 \mathrm{~ms}$ (averaged calcium signal in the simulation environment and with calcium entry extended over the entire simulated dendrite) to match our experimental observations.

To simulate granule cells containing fixed buffer and $\mathrm{Cb}$, we added the following buffer: $160 \mu \mathrm{M}, K_{\mathrm{d}}=700 \mathrm{nM}, D_{\mathrm{Cb}}=0.02 \mu \mathrm{m}^{2} / \mathrm{ms}, k_{\text {on }}=$ $0.027(\mathrm{~ms} \mu \mathrm{M})^{-1}$. To simulate $\mathrm{Cb}$ with a fast calcium association rate, we increased $k_{\text {on }}$ to 0.4 (ms $\left.\mu \mathrm{M}\right)^{-1}$ (Müller et al., 2005).

OLM cells were simulated with only fixed buffer at a concentration of $1670 \mu \mathrm{M}$, a reduced calcium extrusion rate of $0.425 \mathrm{~ms}^{-1}$, and a calcium current amplitude of $8.15 \mathrm{pA}$. This set of parameters yielded a similar increase in free calcium concentration as observed in the granule cell simulation and a calcium decay time constant of $90 \mathrm{~ms}$ (assessed as described above) as measured by imaging experiments.

All simulation runs contained two additional calcium binding partners, "calcium sensors," representing immobilized dendritic calciumactivated proteins or other effectors. Their concentration was kept at $1 \mathrm{pm}$ to avoid an effect on free calcium. We assigned both calcium sensors an affinity of $1 \mu \mathrm{M}$ and either a high $k_{\mathrm{on}}, 0.8(\mu \mathrm{M} \mathrm{ms})^{-1}$, like the N-lobe of calmodulin (Faas et al., 2011), or a low $k_{\text {on }}, 0.02$ ( $\left.\mu \mathrm{M} \mathrm{ms}\right)^{-1}$, as PV (Lee et al., 2000a). A slightly different simulation setup was used for Figure $9 E$ to facilitate the generation of the $2 \mathrm{D}$ images: the stretch factor was omitted and the length of the simulated dendrite was reduced to $20 \mu \mathrm{m}$, which was long enough to avoid calcium ions reaching the end of the simulation environment within the $60 \mathrm{~ms}$ displayed in the image. Spatial profiles were saved every $0.1 \mathrm{~ms}$. The resulting $2 \mathrm{D}$ image was smoothed with a 7-pixel-wide Gaussian filter. 
Predicting the effect of $\mathrm{Cb}$ on $\mathrm{Ca}^{2+}$ signals in the presence of fixed buffer. Equation 6 (see Results) assumes chemical equilibrium between calcium and buffers and requires as input the amplitude of the calcium increase, the global decay time constant, and the $D_{\mathrm{app}}$. The single-compartment model predicts how adding $\mathrm{Cb}$ would reduce the initial calcium signal amplitude and increase the global decay time constant. According to Equation 2, the decay time constant increases by a factor of $\left(1+\kappa_{\mathrm{Cb}}+\right.$ $\left.\kappa_{\text {fixed }}\right) /\left(1+\kappa_{\text {fixed }}\right)$, or $\sim 2.7$, with $\kappa_{\text {fixed }}=100$ and $\kappa_{\mathrm{Cb}}=175$. The amplitude, given by the reciprocal expression, decreases by a factor of $\sim 0.37$. The $D_{\text {app }}$ of calcium in the presence of fixed buffer and $\mathrm{Cb}$ is given by Equation 4 and yields a value of $14 \mu \mathrm{m}^{2} / \mathrm{s}$.

\section{Results}

Here, we specifically studied the content of fixed, immobile calcium buffers in dentate granule cells after removing all mobile buffers. We achieved this removal of mobile buffer via dilution with buffer-free saline in a whole-cell patch-clamp electrode, which has a total volume orders of magnitude larger than the cell volume. Granule cells are known to contain $\sim 40$ $\mu \mathrm{M}$ of the calcium binding protein $\mathrm{Cb}$ (Müller et al., 2005), and we previously verified that $\sim 30$ min of whole-cell recording reduces postrecording immunohistochemical staining of Cb by $80-90 \%$ in granule cells in hippocampal slices (Müller et al., 2005; Fig. 1A).

We aimed to functionally demonstrate that this maneuver actually eliminates calcium binding by $\mathrm{Cb}$. Calcium buffers are known to slow the sequestration and removal of calcium ions and thereby greatly prolong the decay of calcium signals (Neher, 1998). Therefore, if a long-duration (32-43 min: referred to as the "late" recording period) whole-cell patch-clamp recording effectively removes $\mathrm{Cb}$, then the decay time constants of calcium signals during this late recording period should be as fast as decay time constants from $\mathrm{Cb}-\mathrm{KO}$ mice. To test this prediction, we performed confocal-laser-scanning-based calcium imaging experiments and recorded action-potential-evoked calcium signals during the late whole-cell recording period in proximal dendrites of granule cells (Fig. 1). Cells were loaded with a low concentration $(100 \mu \mathrm{M})$ of the low-affinity calcium indicator OGB-6F $\left(K_{\mathrm{d}}=3.1 \mu \mathrm{M}, \kappa_{\text {dye }}=32\right)$ to minimize the addition of exogenous buffers and to avoid saturation of the indicator dye by cellular calcium signals. Three action potentials induced by brief somatic current injections induced pronounced, fast-rising and monoexponentially decaying calcium signals in granule cells from both WT and Cb-KO mice (Fig. 1C,D). Consistent with the removal of $\mathrm{Cb}$, the decay time constants did not differ between the two groups of animals (WT “late," $198 \pm 26 \mathrm{~ms}, n=4 ; \mathrm{KO}, 201 \pm 20$ $\mathrm{ms}, n=6$; not significant; Fig. $1 B-D)$. Additional evidence for successful removal of mobile calcium buffers during the late recording period based on quantifying changes in the endogenous calcium binding ratio will be presented below.

To validate our analysis of fixed buffers based on calcium decay and amplitude measurements, we first tested whether saturation of the indicator dye or diffusion of calcium from highly localized entry points ("hotspots") might distort these parameters. We detected no signs of OGB-6F saturation, because increasing the amount of calcium entry with increasing numbers of action potentials caused the expected increase in the amplitude of the calcium signal and did not prolong the fluorescent decay time constant (Fig. $1 F$ ). We also did not detect hotspots in response to global calcium transients (Fig. $1 E$; for more detailed analysis, see Materials and Methods). Thus, our measurements of decay and amplitude faithfully reflect calcium removal and not diffusion.
We used the "single-compartment model" and the added buffer approach to quantify the fixed buffering capacity, $\kappa_{\text {fixed }}(\mathrm{Ne}-$ her and Augustine, 1992; for review, see Neher, 1998). $\kappa$ (Eq. 1) is a unit-less number and states the rise of calcium ions bound to buffers per increase in free calcium ions above resting concentration. We determined the calcium binding ratio of fixed buffers, $\kappa_{\text {fixed }}$, during the late recording phase to ensure that mobile buffer had been removed. Granule cells were equilibrated with increasing concentrations of the calcium indicator OGB-6F. The buffering capacity of OGB-6F can similarly be quantified by $\kappa_{\text {dye }}$ (Eq. 1). As expected, increasing $\kappa_{\text {dye }}$ reduced the amplitude of calcium transients evoked by three action potentials and prolonged the decay time constant (Fig. 2A). The singlecompartment model predicts that the decay time constant and the reciprocal amplitude of the calcium signal will increase linearly with $\kappa_{\text {dye }}$, and this prediction was closely met by our data (Fig. $2 B, C)$. The $y$-intercept of the fitted line $\left(\kappa_{\text {dye }}=0\right.$, unperturbed condition) approximates the decay time constant and the (inverse) amplitude of the relative calcium concentration increase in the absence of dye: $\tau=159 \pm 35 \mathrm{~ms} ; \Delta F / F=66 \pm 4 \%$ $(n=23)$. More importantly, additional extrapolation of the fitted line to the abscissa intersection yields an estimate of the endogenous calcium binding ratio (Eqs. 2, 3) from the measures of $\tau$ and $(\Delta F / F)^{-1}$. Because we had removed the mobile buffers, this intersection estimates $\kappa_{\text {fixed }}$ to be as large as 90-124[ $\tau=90 \pm 11$; $\left.(\Delta F / F)^{-1}=124 \pm 21 ; n=23\right]$.

The accuracy of our estimate of $\kappa_{\text {fixed }}$ strongly depends on the effective removal of mobile calcium buffers. To substantiate our estimate and to directly and functionally demonstrate that buffering capacity is removed during long whole-cell recordings, we performed an additional series of added-buffer experiments. For this series, we restricted our analysis of calcium signals to the early recording period of 4-10 min after breakthrough to minimize washout of endogenous buffers. Again, increasing the calcium indicator dye concentration decreased the amplitude and increased the decay time constant of the calcium signal evoked by action potentials (Fig. $3 A$ ). However, $\kappa_{\text {endo }}$ (calculated as above but for the early period) was substantially higher and amounted to $165 \pm 86(n=14$; Fig. $3 B)$ and $189 \pm 12$ (data not shown) for the analyses of the decay time constant and the reciprocal amplitude, respectively. In contrast, this difference in calcium buffer content between early and late recording periods was not observed in mice lacking $\mathrm{Cb}$ : repeating the early and late period analysis in $\mathrm{Cb}-\mathrm{KO}$ mice demonstrated that the estimates of the endogenous buffer capacity are strikingly similar between the early (data not shown) and late (Fig. 3C) recording phases (early: $102 \pm 55, n=16$; late: $92 \pm 5, n=22$, using $\tau$ vs $\kappa_{\text {dye }}$ ). Together, the data indicate that long-term whole-cell recordings significantly reduce the buffering capacity of granule cells to a level identical to the one found in $\mathrm{Cb}$-deficient cells, implying that $\mathrm{Cb}$ represents the major, functionally relevant, endogenous mobile calcium buffer and that there is no upregulation of other calcium binding constituents in the $\mathrm{KO}$ animals; the data further show that, during the late period, we specifically measure immobile, non-Cb calcium buffer species.

The exact molecular identity of immobile intracellular calcium buffers is not known, but it is believed that ubiquitous proteins and lipids anchored to the membrane or cytoskeleton act as fixed, low-affinity calcium chelators (Schwaller, 2010). For this reason, the background buffering capacity of fixed calcium buffers is assumed to be a general cellular property and is not expected to differ between types of neurons. To test whether the substantial fixed buffer capacity we found in granule cells is a 
A
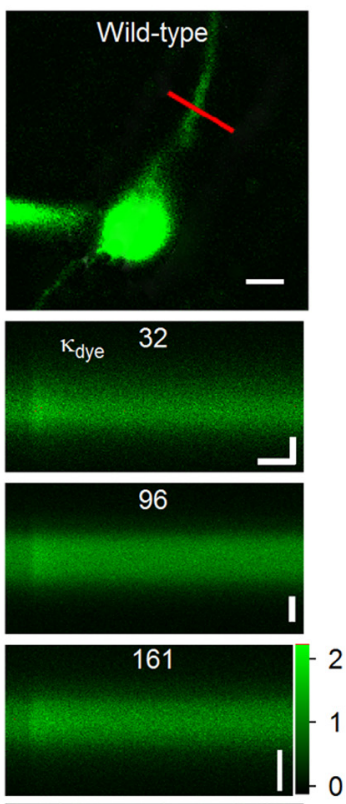

400

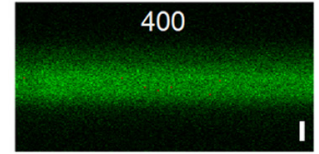

B

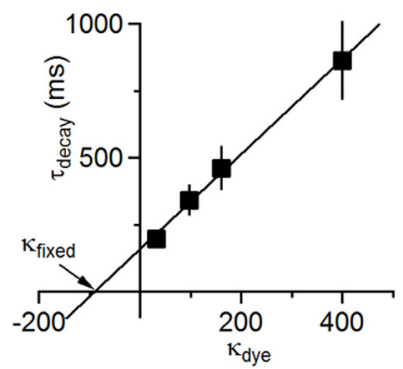

late
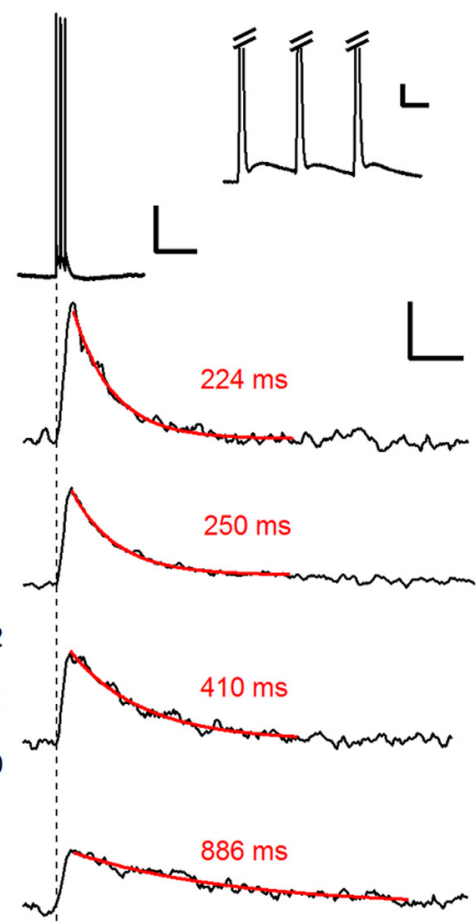

C

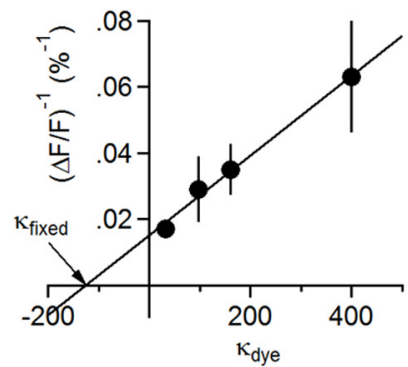

Figure 2. Granule cells retain a substantial calcium buffer capacity, $\kappa_{\text {fixed }}$, after removal of Cb. A, Data for this figure were collected during the late recording period, as indicated by the time line above (red). Calcium signal amplitude and decay time constant varies with indicator dye concentration. Left column, Top, overview frame scan of the granule cell recorded with $\kappa_{\text {dye }}$ 32 (red line indicates position of line scan; scale bar, $10 \mu \mathrm{m}$ ). Below, Repetitive line scans recorded in four different granule cells with $0 \mathrm{~GB}-6 \mathrm{~F}$ concentrations yielding $\kappa_{\text {dye }}$ values of 32 , 96, 161, and 400 (300 ms, $1 \mu \mathrm{m}$, color legend $\Delta F / F$ ). Right column, Top row, Three action potentials at $50 \mathrm{~Hz}$ (calibration: $200 \mathrm{~ms}, 20 \mathrm{mV}$ ) used to evoke calcium transients shown below ( $300 \mathrm{~ms}, 0.2 \Delta F / F$ ). Inset illustrates the action potentials on an expanded timescale (calibration: $10 \mathrm{~ms}, 10 \mathrm{mV}$ ). $\boldsymbol{B}$, Plotting the average decay time constants versus the added binding ratio $\left(\kappa_{\text {dye }}, 0\right.$ GB-6F) allows extrapolation of the fixed buffer capacity, $\kappa_{\text {fixed }}=90 \pm 11, n=23$. The unperturbed decay time constant is the $y$-axis intercept, $\tau=159 \pm 35 \mathrm{~ms}$. C, Plotting the inverse $\Delta F / F$ values versus $\kappa_{\text {dye }}$ yields an independent estimate of the fixed buffer capacity, $\kappa_{\text {fixed }}=124 \pm 21, n=23$. The amplitude of the unperturbed transient amplitude can be obtained from the inverse $y$-axis intercept, $\Delta F / F=66 \pm 4 \%$.

general neuronal property, we repeated our analysis in hippocampal interneurons. We selected OLM CA1 interneurons because they clearly differ from granule cells in firing pattern and geometry and are generally thought to lack mobile calcium binding proteins (Kosaka et al., 1987). OLM cells were visually identified, and axons were reconstructed after recording for verification (for criteria, see Materials and Methods) and exhibited a bipolar dendritic morphology in stratum oriens and an axonal
A
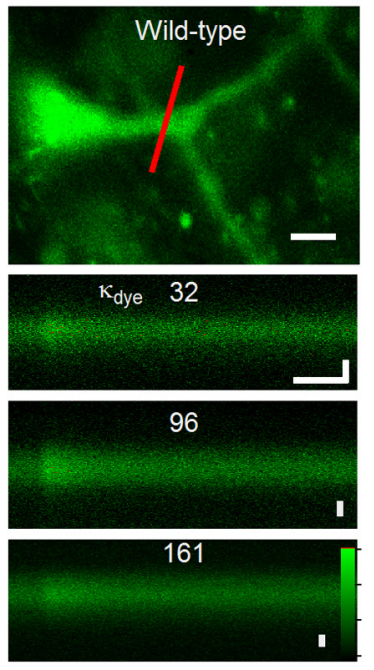

B
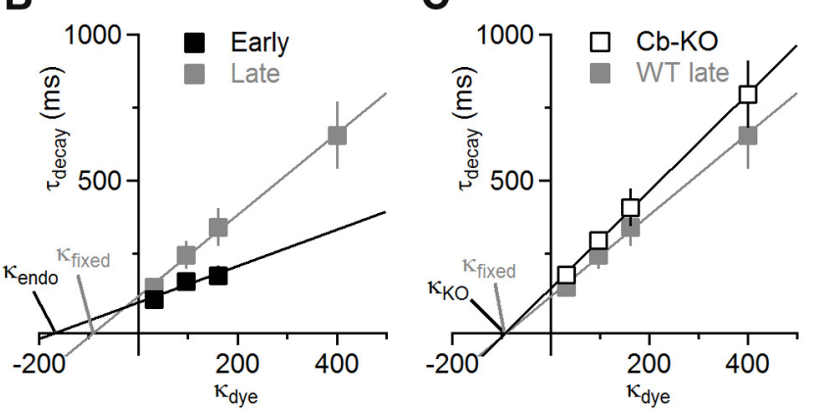

Figure 3. Separation of mobile and immobile buffer capacity and verification of removal of Cb from granule cells. A, Data for this panel were collected during the early recording period of granule cells in WT mice, as indicated by the time line above (blue). Top overview image ( $5 \mu \mathrm{m})$ shows an example of the line scan position for $\kappa_{\text {dye }} 32$. Below, repetitive line scans for $\kappa_{\text {dye }}$ values of 32,96 , and 161 ( $300 \mathrm{~ms}, 1 \mu \mathrm{m}$, color legend $\Delta F / F)$. Top right shows action potentials used to elicit calcium entry ( $300 \mathrm{~ms}, 20 \mathrm{mV}$ ). Inset calibration: $10 \mathrm{~ms}, 10 \mathrm{mV}$. Below, Calcium transients in response to three action potentials with different dye concentrations $(300 \mathrm{~ms}, 0.2$ $\Delta F / F)$. $B$, Extrapolation of the endogenous calcium binding ratio. Note that $\kappa_{\text {endo }}$ extracted from the early recording period $(165 \pm 86, n=14)$ is much larger than the value obtained for the late recording period (see Fig. $2 B, \kappa_{\text {fixed }}=90 \pm 11$ ), indicating removal of endogenous mobile buffers. $C, \kappa_{\text {endo }}$ measured in granule cells from $\mathrm{Cb}-\mathrm{KO}$ animals equals $\kappa_{\text {fixed }}$ measured after long-duration recordings (WT, $\kappa_{\text {fixed }}=90 \pm 11, n=23 ; \mathrm{Cb}-\mathrm{K} 0, \kappa_{\text {endo }}=92 \pm 5, n=$ 22 ), suggesting that $\mathrm{Cb}$ is completely removed during the late recording period.

tree branching and terminating primarily in stratum lacunosum moleculare (Fig. 4A). These cells can fire at high frequencies and display a prominent sag potential on hyperpolarizing current injection (Maccaferri and McBain, 1996; Fig. 4B). We analyzed OLM calcium transients during the late recording period to ensure that any mobile calcium binding protein would be washed out. Because it has been reported that a subpopulation of OLM cells may express low levels of PV (Maccaferri et al., 2000), we performed postrecording immunohistochemical stainings after whole-cell dialysis for $40 \mathrm{~min}$ and could not detect PV in the recorded neurons (Fig. $4 C ; n=4$ ).

Calcium transients evoked by three action potentials and measured during the late recording period in the proximal part of the horizontally oriented dendrites of OLM cells rose at a similar rate, but their decay and amplitude showed a different dependence on the indicator dye concentration when compared with granule cells (Fig. 5A). In the absence of indicator dye (unperturbed condition), the extrapolated decay and the amplitude 
A

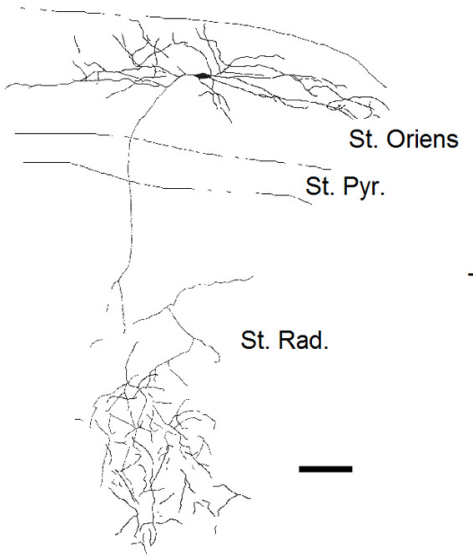

B
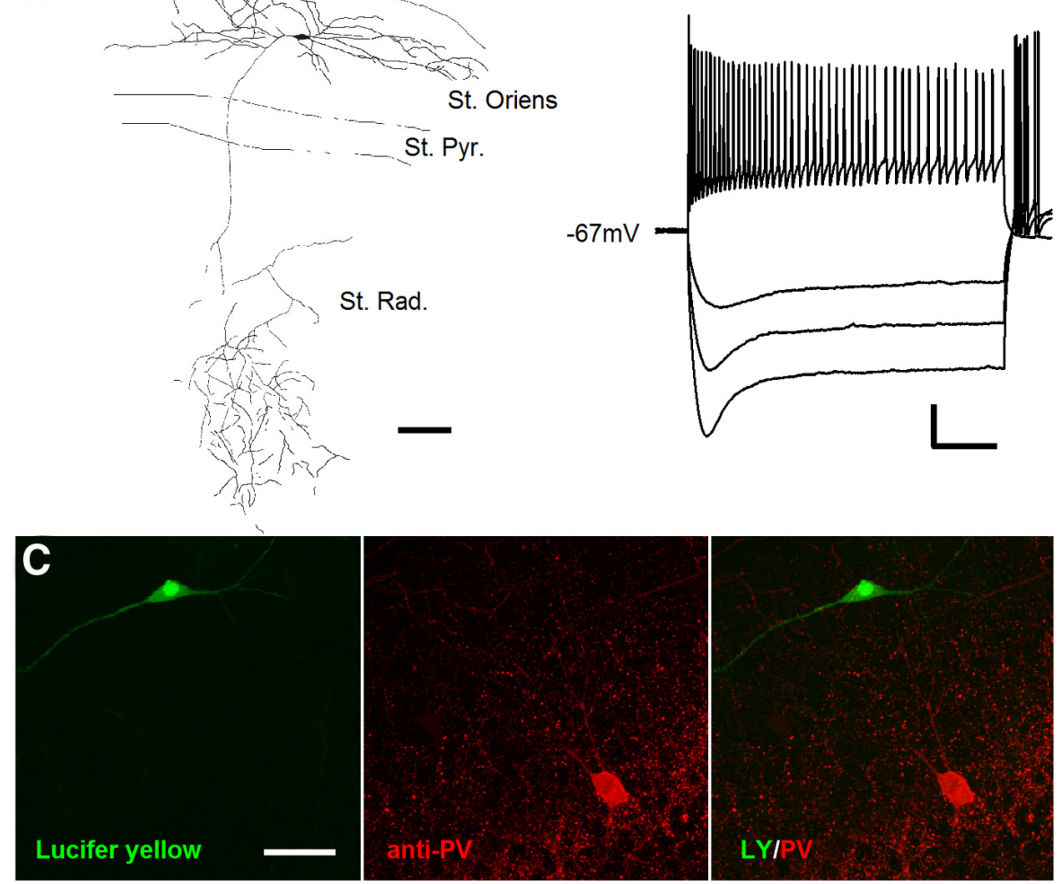

Figure 4. Identification of OLM cells. $A$, Morphological reconstruction of a recorded OLM interneuron shows the spindle-shaped soma in stratum oriens and the axon branching into stratum lacunosum moleculare. Scale bar, $100 \mu \mathrm{m}$. St. Oriens, Stratum oriens; St. Pyr., stratum pyramidal; St. Rad., stratum radiatum. $\boldsymbol{B}$, Electrophysiological response of an 0 LM cell to injected currents $(-200$, $-150,-100$, and $+200 \mathrm{pA}$ ) shows the typical prominent sag and high-frequency firing. Calibration: $200 \mathrm{~ms}, 20 \mathrm{mV}$. C, OLM cells were filled with Lucifer yellow (LY) during long whole-cell recordings, and slices were labeled with PV antibodies. There was no colabeling of Lucifer yellow and the PV antibody, $n=4$. Scale bar, $20 \mu \mathrm{m}$.

were comparable with granule cells $(\tau=114 \pm 59 \mathrm{~ms} ; \Delta F / F=$ $52 \pm 29 \% ; n=14$ ), but the decay time constant and the reciprocal amplitude increased more strongly with increasing indicator dye concentration in OLM cells, indicating a weaker fixed buffer background. Indeed, fitting the decay time constant and the inverse amplitude of the calcium signals both estimated $\kappa_{\text {fixed }}$ to be much lower than in granule cells and yielded values of $28 \pm 6$ and $31 \pm 32(n=14)$, respectively (Fig. $5 B, C)$. We repeated this analysis during the early recording period, and, in contrast to granule cells, the calculated $\kappa$ value was very similar to that obtained during the late recording period, confirming our expectation that there is little or no mobile buffering species in OLM interneurons (Fig. $5 B, C$ ).

Equation 4 assesses the impact of the fixed buffer backgrounds, $\kappa_{\text {fixed }}$, determined for granule cells and OLM cells on spatial calcium signaling in the absence of mobile calcium buffers (Zhou and Neher, 1993, with $\kappa_{\text {mobile }}=0$ and $D_{\mathrm{Ca} 2+}$ being the diffusion coefficient of unbound calcium):

$$
D_{\text {app }}=D_{\mathrm{Ca}^{2}+} \frac{1}{1+\kappa_{\text {fixed }}},
$$

This equation is valid if there is rapid chemical equilibrium of calcium binding to buffer molecules. $D_{\text {app }}$ describes how both free and buffer-bound calcium ions (assumed to be in equilibrium) diffuse in dendrites. Because $\kappa_{\text {fixed }}$ occurs in the denominator, our experimentally determined values predict that fixed buffers in granule cells and OLM cells will dramatically slow diffusion of calcium by a factor of $\sim 100$ and $\sim 30$, respectively, when compared with calcium diffusion in the absences of buffers. Furthermore, Equation $4 \mathrm{a}$ reveals a dramatically different mobil- ity of calcium ions between granule cells and OLM cells. The $D_{\text {app }}$ values for granule and OLM cells, as calculated from the $\kappa_{\text {fixed }}$ value from the decay constant, are $2.5 \pm 0.3$ and $7.7 \pm 1.6 \mu \mathrm{m}^{2} / \mathrm{s}$, respectively $\left(D_{\mathrm{Ca} 2+}=223 \mathrm{\mu m}^{2} / \mathrm{s}\right.$ for unbound calcium in cytosol (Allbritton et al., 1992; Fig. 6). Using the values from the inverse amplitude, the calculated $D_{\text {app }}$ values for granule and OLM cells are $1.8 \pm 0.3$ and $6.8 \pm 6.6 \mu \mathrm{m}^{2} / \mathrm{s}$ (data not shown). $\kappa_{\text {fixed }}$ from the inverse amplitude has greater uncertainty, because $\Delta F / F$ depends on the resting calcium concentration and the amount of calcium entry in each cell. For that reason, we prefer $\kappa_{\text {fixed }}$ from the decay time constant for the following analyses.

The mean 1D displacement of calcium ions after entering a dendrite is given by: $\frac{2}{\sqrt{\pi}} \sqrt{D_{\text {app }} t}$. If we estimate the time after which the majority of calcium ions have been extruded with $2 \times \tau$, then our $D_{\text {app }}$ values, together with the above equation, predict that calcium ions have approximate action ranges as small as 0.9 and 1.3 $\mu \mathrm{m}$ in granule cell and OLM cell dendrites, respectively (given by $\frac{2}{\sqrt{\pi}} \sqrt{D_{\text {app }} 2 \tau}$ with $\tau=130$ and $90 \mathrm{~ms}$ ).

To more comprehensively analyze the temporal evolution of spatial calcium gradients in dendrites, we evaluated an analytical expression (Crank, 1975, his Eq. 2.15) for an increase in free calcium $(600 \mathrm{nM})$ above the resting concentration (100 nM):

$$
\left[C a^{2+}\right](x, t)=\frac{1}{2} C_{0}\left(\operatorname{erf}\left(\frac{h-x}{2 \sqrt{\pi D_{\text {app }} t}}\right)+\operatorname{erf}\left(\frac{h+x}{2 \sqrt{\pi D_{\text {app }} t}}\right)\right) .
$$

This expression represents the temporal evolution of the calcium concentration gradient along a dendrite $(x)$ with a small diameter such that radial gradients are negligible. For simplicity, this expression does not include a calcium removal mechanism. We cause this dendrite to experience an instantaneous, spatially homogeneous elevation of free calcium to $600 \mathrm{nM}\left(C_{0}\right)$ along a subsynaptic segment of $300 \mathrm{~nm}(h=150 \mathrm{~nm})$ (representing the size of a typical PSD: Sheng and Hoogenraad, 2007).

We first evaluated Equation 5 for three conditions to illustrate the effect of solely changing the $D_{\text {app }}$ of calcium: free/unbound calcium diffusion in the cytosol $\left(D_{\text {free }}=220 \mu \mathrm{m}^{2} / \mathrm{s}\right.$, gray), calcium diffusion in the presence of low fixed buffer background (high $D_{\text {app }}=7 \mu \mathrm{m}^{2} / \mathrm{s}$, green, as in OLM cells), and high fixed buffer background (low $D_{\text {app }}=2 \mu \mathrm{m}^{2} / \mathrm{s}$, blue, as in granule cells). Figure $7 A$ shows that the successive spatial calcium concentration profiles are identical for the three different conditions of calcium diffusion, if $t$ is chosen appropriately, but are reached substantially and progressively later as the fixed buffer content is increased. The same curves occur because both variables $t$ and 
$D_{\text {app }}$ only appear as the product $D_{\text {app }} \times t$ in Equation 5. The spatial profiles change with the addition of calcium extrusion to Equation 5 (final term of Eq. 6):

$$
\begin{array}{r}
{\left[C a^{2+}\right](x, t)=\frac{1}{2} C_{0}\left(\operatorname{erf}\left(\frac{h-x}{2 \sqrt{\pi D_{\mathrm{app}} t}}\right)\right.} \\
\left.+\operatorname{erf}\left(\frac{h+x}{2 \sqrt{\pi D_{\mathrm{app}} t}}\right)\right) e^{\left(\frac{-t}{\tau}\right)} .
\end{array}
$$

For Figure $7 B$, we used the previous values for $D_{\text {app }}$ and $\tau=130 \mathrm{~ms}$ for all three conditions and evaluated Equation 6 for every position, $x$ (step size of $10 \mathrm{~nm}$ ), over time to determine the maximal local free calcium concentration reached at each position. We then plotted this maximal concentration for every position for each $D_{\text {app }}$ condition. Although freely diffusing calcium is minimally affected by removal mechanisms, the delay in diffusion allows pumps close to the source to more successfully bind and remove a larger fraction of calcium ions, creating a substantial localizing effect on the calcium signal.

The situation is different if a cell upregulates or downregulates the concentration of intracellular fixed buffers. Should this occur, the calcium extrusion rate $(\gamma)$ remains constant and the $\kappa$ value of fixed buffers will change both $D_{\text {app }}$ and $\tau$ according to Equations 4 and 2. In fact, in the absence of mobile buffers, $\kappa_{\text {fixed }}$ decreases $D_{\text {app }}$ by the same amount it increases $\tau$ such that the product $D_{\text {app }} \times \tau$ is independent of $\kappa_{\text {fixed }}$ and is given by $D_{\mathrm{Ca}^{2}} / \gamma$. Thus, in the absence of mobile buffers, the spatial action range of calcium ions (see above, $\frac{2}{\sqrt{\pi}} \sqrt{D_{\mathrm{app}} 2 \tau}$ ) is independent of the concentration of fixed calcium buffers.

To illustrate the effect of upregulation of fixed buffers in Figure $7 C$, we allowed $\kappa_{\text {fixed }}$ to determine both $D_{\text {app }}$ and $\tau$ but kept $C_{0}$ at the site of entry at $600 \mathrm{~nm}$ free calcium. Figure $7 C$ plots the time course of the resulting calcium signal when evaluated at fixed distances from the source $(0,0.5$, and $1 \mu \mathrm{m})$ for $\kappa_{\text {fixed }}=30$ (green), 100 (blue), and 300 (pink). Note that not only the initial calcium concentration at 0 $\mu \mathrm{m}$, which is determined by $C_{0}$, but also the peak calcium concentrations at more remote positions are not influenced by the increased amount of fixed buffers, reflecting the abovementioned fact that fixed buffers do not change the spatial range of calcium. However, a stronger fixed buffer background clearly leads to substantially prolonged calcium signals. The local calcium concentration rises more slowly as a result of the decreased $D_{\text {app }}$, maintains the peak concentration for a longer time, and decays significantly more slowly because of the pro29\%).

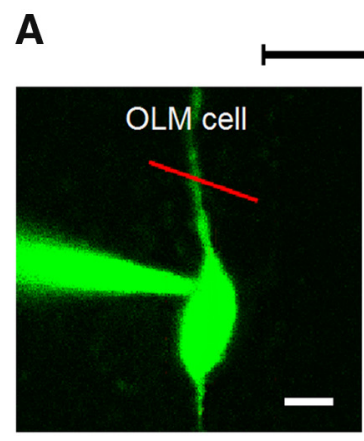

late
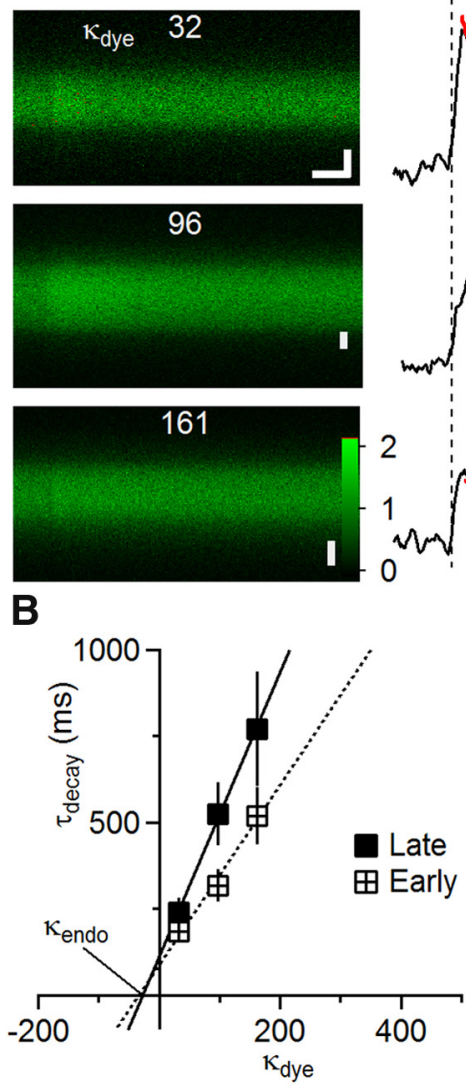

C

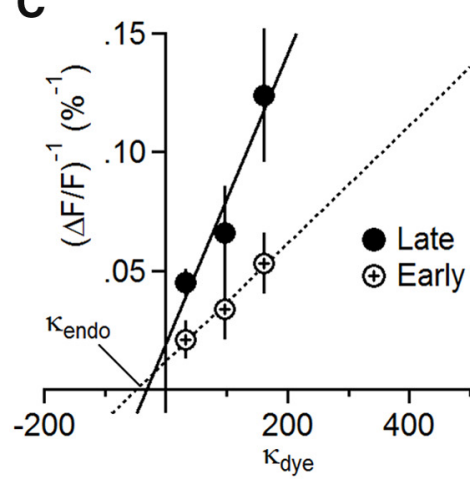

Figure 5. OLM cells exhibit low fixed buffering capacity and express no mobile buffer. $\boldsymbol{A}$, Data for this figure were collected during the late recording period, as indicated by the time line above (red). Top overview image shows an example of the line scan position (red line) on one of the two 0LM primary dendrites (scale bar, $10 \mu \mathrm{m}$ ). Top right and inset show the three action potentials at $50 \mathrm{~Hz}$ used to elicit calcium entry (calibration: $200 \mathrm{~ms}, 20 \mathrm{mV}$; inset, $5 \mathrm{~ms}, 20 \mathrm{mV}$ ). Bottom left panels show line scans obtained from $0 \mathrm{LM}$ cell dendrites with $0 \mathrm{~GB}-6 \mathrm{~F}$ yielding the indicated $\kappa_{\text {dye }}$ values ( $300 \mathrm{~ms}, 1 \mu \mathrm{m}$, color legend $\Delta F / F$ ). Bottom right panels show calcium transients (calibration: $300 \mathrm{~ms}, 0.2 \Delta F / F$ ) overlaid with a single-exponential fit (red) and the decay time constant listed next to the transient. $B$, Extrapolation of the endogenous calcium binding ratio from the decay time constant for the early and the late recording in OLM interneurons. There was no difference in the early and late $\kappa_{\text {endo }}$ values (early $\kappa_{\text {endo }}=34 \pm 16$; late $\left.\kappa_{\text {endo }}=28 \pm 6 ; n=14\right)$, thus the estimated $\kappa_{\text {endo }}$ corresponds to $\kappa_{\text {fixed }}$. The unperturbed decay time constant is the $y$-axis intercept (early $\tau=90 \pm 19 \mathrm{~ms}$; late $\tau=114 \pm 59 \mathrm{~ms}$ ). C, Similarly, $\kappa_{\text {endo }}$ in OLM interneurons did not differ between the early and late recording period when extrapolated from inverse $\Delta F / F$ values (early $\kappa_{\text {endo }}=48 \pm 17$; late $\kappa_{\text {endo }}=31 \pm 32 ; n=14$ ). The amplitude of the unperturbed transient amplitude is the inverse $y$-axis intercept (early $\Delta F / F=83 \pm 12 \%$; late $\Delta F / F=52 \pm$

longed extrusion time constant. In this way, fixed calcium buffers increase the local dwell time of free calcium ions inside the dendrite, making them available for longer, which is particularly important for slow-binding partners (see below). The same values of $\kappa_{\text {fixed }}$ and the resulting $D_{\text {app }}$ and $\tau$ from Figure $7 C$ were used in $D$. This graph depicts how severely fixed buffers slow the spread of the calcium cloud by comparing how rapidly the peak concentrations (as graphed in $C$ ) move along the dendrites. The slope of these lines is a measure of the velocity of 


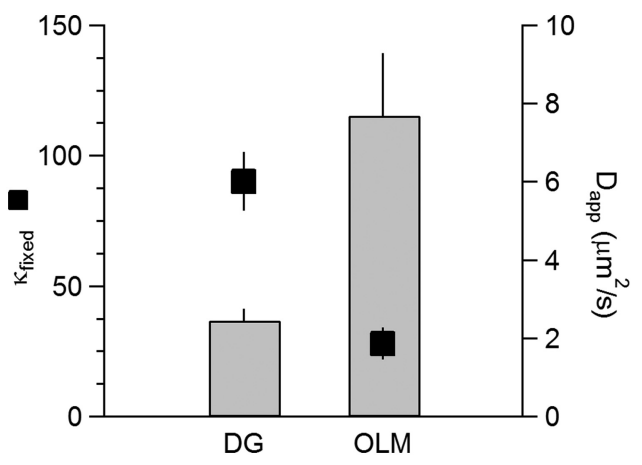

Figure 6. Cell-type-specific $\kappa_{\text {fixed }}$ translates into substantially different apparent diffusion coefficients for calcium. Summary of the measured fixed buffering capacity, $\kappa_{\text {fixed }}$ in granule and OLM cells, as measured by the decay time constant (black squares). The predicted apparent diffusion coefficient $\left(D_{\text {app }}\right.$, gray) for calcium was calculated using the $\kappa_{\text {fixed }}$ derived from the decay time constant for each cell type and was found to be $2.5 \pm 0.3 \mu \mathrm{m}^{2} / \mathrm{s}$ for granule cells and $7.7 \pm 1.6 \mu \mathrm{m}^{2} / \mathrm{s}$ for $0 \mathrm{LM}$ cells. Note that the $D_{\text {app }}$ is inversely related to $\kappa_{\text {fixed }}$.

the calcium spread and is approximated by $2 \sqrt{D_{\text {app }} / \tau}$, which, in the absence of mobile buffers, reduces to $\frac{2 \sqrt{\gamma D_{\mathrm{Ca}^{+}}}}{1+\kappa_{\mathrm{fixed}}}$,implying that the velocity decreases inversely with $\kappa_{\text {fixed }}$.

To compare spatial calcium signaling between granule cells and OLM cells, we used the experimentally determined cellspecific parameters for the decay of the calcium signal (granule cells, $\tau=130 \mathrm{~ms}$; OLM, $\tau=90 \mathrm{~ms}$ ) and the $D_{\text {app }}$ from Equation 4 (granule cells, without $\mathrm{Cb}, 2.1 \mu \mathrm{m}^{2} / \mathrm{s}$; OLM, $7.2 \mu \mathrm{m}^{2} / \mathrm{s}$ ). The initial increase in free calcium concentration was kept the same for both cell types ( $600 \mathrm{~nm}$ ) because the amplitudes of the unperturbed calcium transients were not significantly different between granule cells and OLM cells. As can be seen in Figure 8, A and $B$, the cell-specific extrusion rate and the cell-specific fixed buffer content work together to primarily equalize the resulting peak calcium concentrations. However, as a fingerprint of their substantial fixed buffer capacity, the duration of calcium signals is strongly prolonged and the spread of the peak concentration is clearly delayed in granule cells. This can more clearly be seen in the peak position versus time plot (Fig. 8C).

There are circumstances, such as chronic temporal lobe epilepsy (Maglóczky et al., 1997) and during development (Müller et al., 2005), under which granule cells lack $\mathrm{Cb}$ and intracellular calcium is bound only by fixed buffers as analyzed above. However, mature granule cells in the adult rodent hippocampus contain $\sim 160 \mu \mathrm{M} \mathrm{Cb}$ (Müller et al., 2005). It is tempting to simply add $\kappa_{\mathrm{Cb}}$ to $\kappa_{\text {endo }}$ in Equation 4 and use the resulting $D_{\text {app }}$ to calculate $\tau$ and $\Delta \mathrm{Ca}^{2+}$ from Equations 2 and 3 to explore the effect of $\mathrm{Cb}$ on calcium distribution in granule cells according to Equation 6. However, because of the high calcium binding affinity of $\mathrm{Cb}(0.7 \mu \mathrm{M})$ and its relatively slow calcium binding rate $\left[k_{\mathrm{on}}=0.027(\mathrm{~ms} \mu \mathrm{M})^{-1}\right]$ (Nägerl et al., 2000; Berggård et al., 2002), the linearity and equilibrium requirements of the singlecompartment model may not be met. In the case that the singlecompartment model is not valid, detailed numerical simulations of $1 \mathrm{D}$ calcium diffusion along a dendrite would be required to investigate the effect of $\mathrm{Cb}$ on the spatiotemporal spread of free calcium (Fig. 9). The geometry of the dendrite and the calcium influx was the same as in Figures 7 and 8, but calcium entered the dendrite for $0.8 \mathrm{~ms}$. Calcium influx occurred equally over the 300 $\mathrm{nm}$ subsynaptic dendritic segment and was adjusted to produce an increase in free calcium concentration of $\sim 600 \mathrm{~nm}$ in the presence of fixed buffer only. The extrusion rate was chosen to reproduce the experimentally observed calcium decay time constant of $130 \mathrm{~ms}$ (for details, see Materials and Methods). Figure $9 A$ shows the time course of the free calcium concentration measured at the center $(0 \mu \mathrm{m})$. For comparison, we also ran the simulation without $\mathrm{Cb}$, in the sole presence of the fixed buffer amount found in granule cells. As can be seen, the simulation validates the evaluation of Equation 6 to describe the distribution of free calcium in the absence of $\mathrm{Cb}$. However, if we add $\mathrm{Cb}$ to the simulation environment, the resulting curve does not match the prediction based on the single-compartment model (dashed red line; for calculation, see Materials and Methods); the simulation shows that $\mathrm{Cb}$ (red line) does not affect the initial peak amplitude and causes an accelerated decay of the calcium concentration. This is more clearly seen in Figure $9 B$ in which the spatial average calcium concentration is plotted. The average calcium concentration in the simulation environment eliminates diffusional processes and reflects the chemical kinetics of calcium binding, unbinding, and extrusion. The simulated free calcium concentration in the presence of $\mathrm{Cb}$ (red line) meets the prediction of free calcium according to Equation 6 (dashed red line) only after $\sim 50$ ms. The bottom panel depicts $\left[\mathrm{Cb}-\mathrm{Ca}^{2+}\right]$ and shows that, during this initial $50 \mathrm{~ms}, \mathrm{Cb}$ continues to bind additional calcium ions and reaches its peak occupancy at the time when the simulated free calcium curve meets the prediction (Fig. $9 B$, bottom, light blue line). If we increase the $k_{\text {on }}$ of $\mathrm{Cb}$ to $0.4(\mathrm{~ms} \mu \mathrm{M})^{-1}$, the free calcium concentration (green line) drops much faster and meets the prediction curve after a few milliseconds. Similarly, in the absence of fixed buffer, the $\left[\mathrm{Cb}-\mathrm{Ca}^{2+}\right]$ also rapidly reaches a maximum, because in this situation, binding of calcium by $\mathrm{Cb}$ rapidly reduces the free calcium concentration (data not shown) such that there is no additional association of $\mathrm{Cb}$ and calcium (Fig. 9B, bottom, gray line). Thus, by virtue of both the slow binding rate of $\mathrm{Cb}$ and the strong fixed buffer background in granule cells, the free calcium concentration in approximately the first $20 \mathrm{~ms}$ is unaffected and behaves as if solely in the presence of fixed calcium buffer. As a corollary, the free calcium concentrations close to the source $( \pm 300 \mathrm{~nm}$ from the center), which occur within $\sim 10 \mathrm{~ms}$, are hardly affected by $\mathrm{Cb}$ (Fig. $9 C, D$, solid line). In effect, the spatial gradient of maximum calcium concentrations becomes steeper in the presence of $\mathrm{Cb}$. Note that, although the $D_{\text {app }}$ for calcium is higher in the presence of $\mathrm{Cb}$, the action range of calcium is more limited because the increased calcium binding ratio strongly reduces free calcium levels (Fig. 9D). Although the action range of calcium is not larger in the presence of $\mathrm{Cb}$, because of shuttling of calcium ions, $\mathrm{Cb}$ still accelerates the spread of the calcium cloud measured as the time-to-peak versus the distance (Fig. 9D,G). The color-coded 2D plots of free calcium in Figure 9E summarize the effects of $\mathrm{Cb}$ : $\mathrm{Cb}$ leaves the magnitude and spatial extent of the initial central calcium concentration unaffected but strongly limits the duration of calcium signals (vertical axis) and slightly narrows the spatial spread (horizontal axis) (compare the 200 and $400 \mathrm{~nm}$ contour lines for Fixed buffer and Fixed buffer $+\mathrm{Cb}$ ). OLM cells display an almost identical initial central calcium concentration and a spatial extent that is similar to granule cells both with and without $\mathrm{Cb}$. In contrast, the spatial extent of calcium signals is very different from granule cells lacking $\mathrm{Cb}$. Therefore, by regulating the expression of $\mathrm{Cb}$, granule cells are capable of switching their mode of local calcium signaling from slow and long lasting to fast and brief without affecting the peak calcium concentration. In this way, b acts like a spatial and temporal high-pass filter. Figure $9 F$ illustrates the occupancy of dendritic calcium sensors with either a fast or slow calcium binding rate (for details, see Materials and Methods). A 

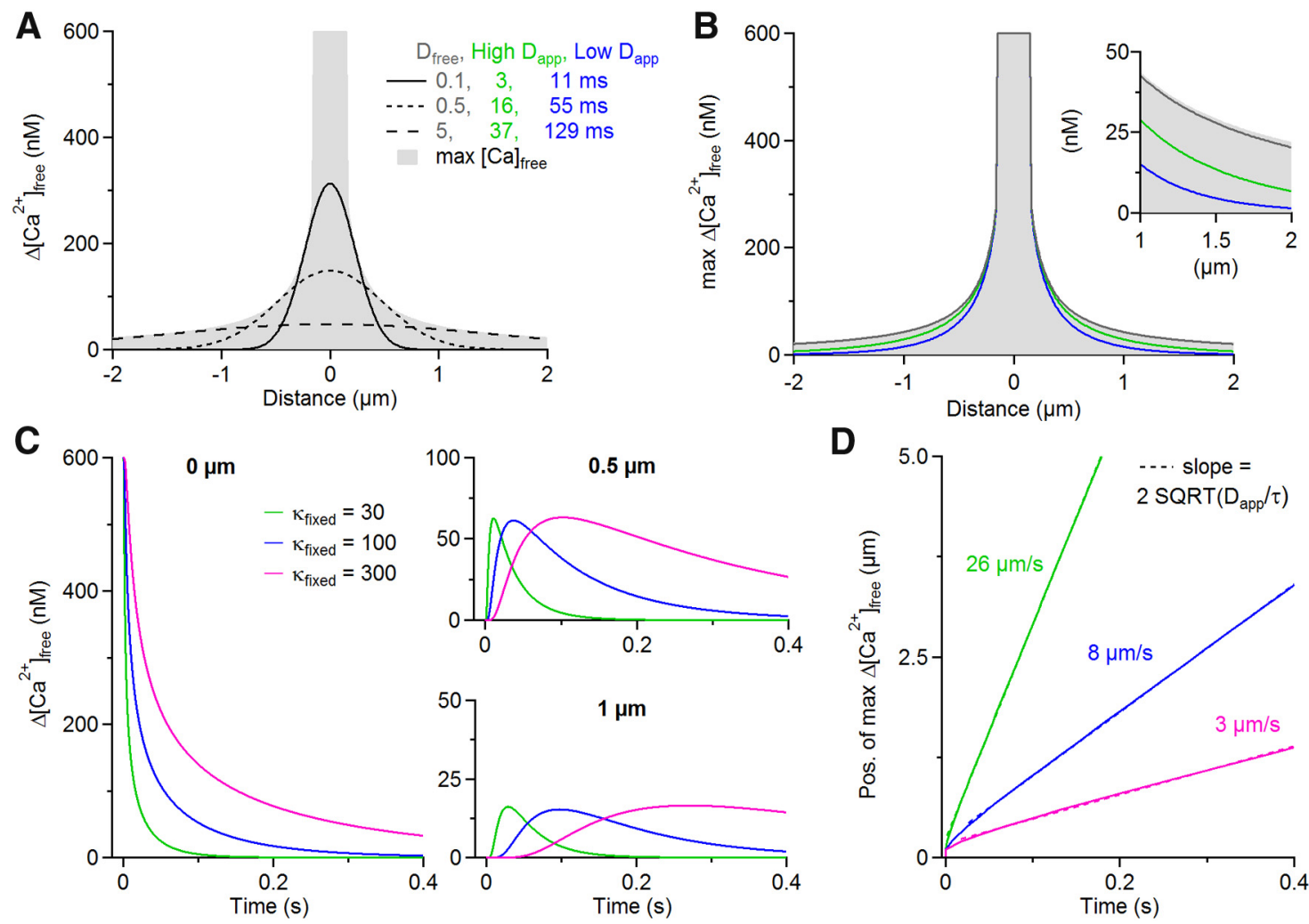

Figure 7. Fixed buffers prolong local calcium signals. $A$, Spatial distribution of maximal calcium concentration achieved over time at every position is independent of the diffusion coefficient and is indicated by the gray shaded region; actual snapshots of calcium concentration profiles at single time points are indicated by the solid, dashed, and dotted lines. Note that the same concentration profiles occur for all three different buffering conditions but at different time points according to the product $D_{\text {app }} \times t$. The gray shaded maximal calcium concentration curve was generated by calculating the time course of free calcium for every position based on Equation 5 and then determining the maximal calcium concentration achieved at each position. The black snapshot curves of the momentary calcium concentration profiles were obtained by evaluating Equation 5 for three $D_{\text {app }}$ values. The time points, $t$, of the snapshots were chosen to keep the product $D_{\text {app }} \times t$ constant. $B$, Addition of homogeneously distributed calcium extrusion ( $\tau=130 \mathrm{~ms}$ in all cases) reveals a strong localizing effect on the spatial distribution of calcium in the cases in which fixed buffer reduces the $D_{\text {app }}$. Inset shows the stronger interaction of different $D_{\text {app }}$ values and extrusion at more distal locations, and the gray envelope is the maximum free calcium in the absence of extrusion. This panel was generated using Equation 6 , as explained in Results. $C$, The time course of the calcium elevation was calculated at three points distal to the entry site $(0.5,1$, and $2 \mu \mathrm{m})$ for three different values of $\kappa_{\text {fixed }}$. For this panel, $D_{\text {app }}$ and $\tau$ were calculated based on the different $\kappa_{\text {fixed }}$ according to Equations 2 and 4 . Note that the initial free calcium concentration at $0 \mu \mathrm{m}$ was kept at $600 \mathrm{~nm}$ to allow all curves to peak at the same values to facilitate the comparison of their time course. The amount of fixed buffer strongly slows down local calcium signaling but does not change the peak concentrations at 0.5 and $1 \mu \mathrm{m}$. D, Plotting the time of the calcium peak versus the distance from the synaptic entry site gives the velocity of the calcium spread (slope of the line, indicated for each case). The plotted relationships were well fitted with a straight line with a slope constrained to $2 \sqrt{D_{\text {app }} / \tau}$ (dashed lines). The same model parameters were used as in $C$.

fast-acting calcium sensor responds to the brief peak in free calcium concentration at the center $(0 \mu \mathrm{m})$ and reaches a very similar occupancy in the presence or absence of $\mathrm{Cb}$. In contrast, the peak occupancy of a slow calcium sensor is also significantly determined by the later calcium signal that is substantially reduced by the delayed binding of calcium by $\mathrm{Cb}$. At more remote locations, $\mathrm{Cb}$ homogeneously reduces the initial and later calcium signal such that there is a similar reduction of the occupancy of both fast and slow calcium sensors. Together, the mixture of a strong fixed buffer background with a high concentration of the mobile but slow-binding calcium buffer $\mathrm{Cb}$ allows hippocampal granule cells to accomplish two apparently conflicting tasks on local calcium entry: granule cells can handle large amounts of calcium with their large compound calcium binding ratio (probably $\geq 275$ ), while they maintain a rapid and high amplitude local calcium signal.

\section{Discussion}

In this study, we isolated and determined the immobile calcium buffer content of two types of central neurons for the first time. We identified both a mobile and an immobile fraction of endogenous calcium buffers in granule cells, but we found only a small amount of immobile calcium buffers in OLM interneurons. Pre- cise knowledge of the buffering content allowed us to predict that immobile buffers dramatically slow calcium diffusion relative to free diffusion by a factor of $\sim 100$ in dendrites of granule cells and $\sim 30$ in OLM interneurons when no other buffers are present. A theoretical analysis of calcium diffusion in subsynaptic dendritic segments showed that the large amount of fixed buffers in granule cells renders $\mathrm{Cb}$ an effective spatiotemporal high-pass filter.

We isolated fixed buffers by systematically washing out the endogenous mobile buffer of granule cells during prolonged whole-cell recordings. For this approach to be valid, verification of the successful removal of mobile buffers is mandatory. Several lines of evidence support the almost complete removal of $\mathrm{Cb}$ from granule cells. First, we previously histologically verified that whole-cell recordings of $>40$ min eliminate $\mathrm{Cb}$ from granule cells (Müller et al., 2005), which is in agreement with the estimated time course of washout for a $28 \mathrm{kDa}$ protein (Pusch and Neher, 1988). Second, the decay time constant of calcium signals after prolonged whole-cell recordings in WT mice was comparable with that of $\mathrm{Cb}-\mathrm{KO}$ mice, which is expected if $\mathrm{Cb}$ was eliminated during the long whole-cell recording (Fig. 1B). Third, we found that the calcium binding ratio of granule cells clearly drops from the early to the late recording period, indicating a reduction in 

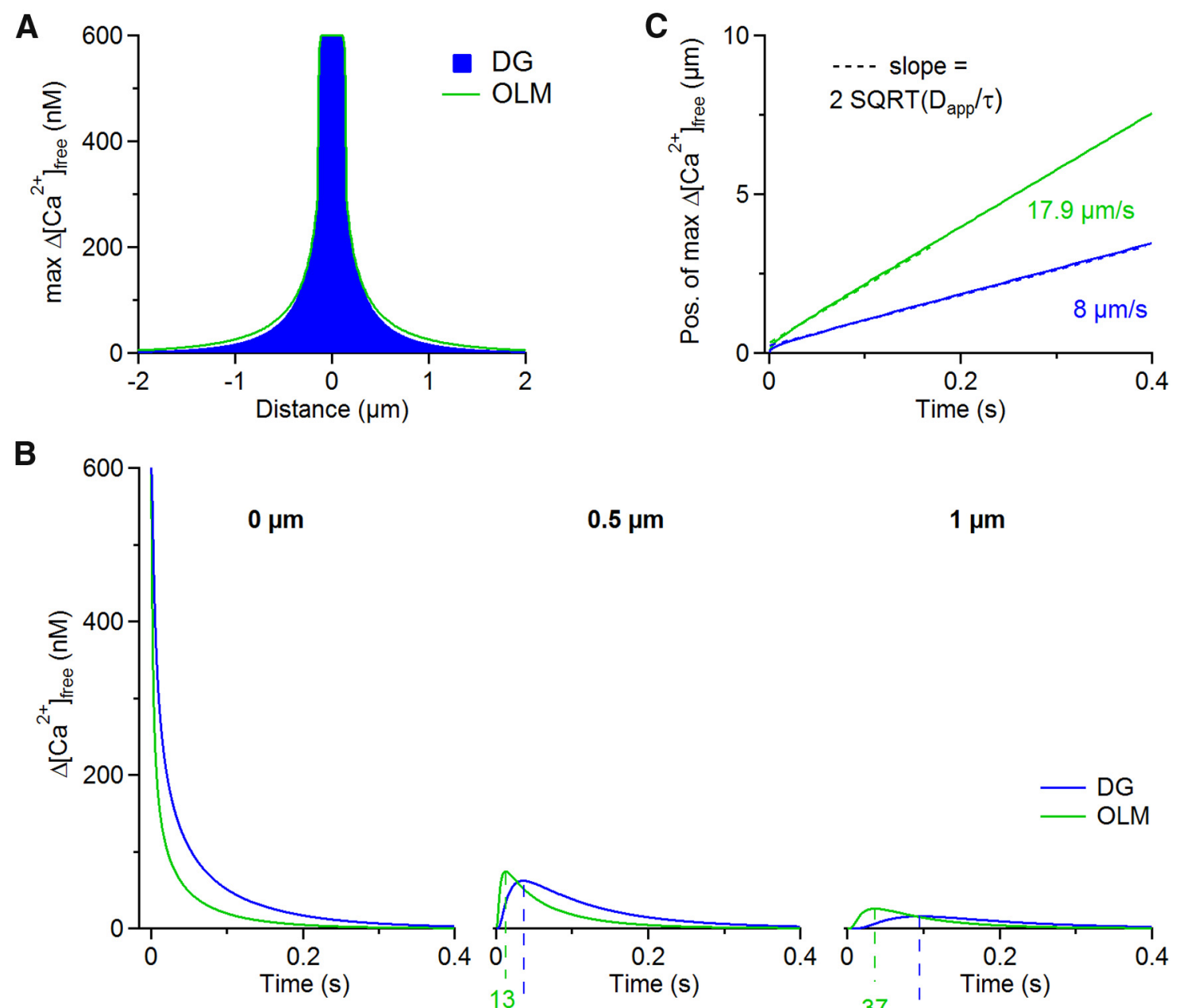

0.40

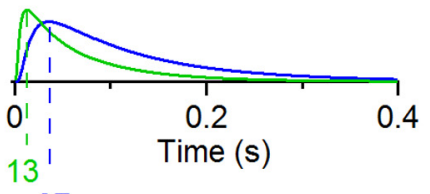

37

$0.5 \mu \mathrm{m}$

$1 \mu \mathrm{m}$

Figure 8. Propagation velocity of the local calcium cloud differs between granule cell and OLM dendrites, whereas the spatial range and the signal amplitude are comparable. $A$, Equation 6 was evaluated for experimentally derived values for the decay time constants and amplitudes of dentate granule cells (DG, blue) and OLM cells (green) (unperturbed values from the early recording period, $\tau_{\mathrm{DG}}=130 \mathrm{~ms}, \tau_{\mathrm{OLM}}=90 \mathrm{~ms}, D_{\text {app DG }}=2.1 \mu \mathrm{m}^{2} / \mathrm{s}, D_{\text {app oLM }}=7.2 \mu \mathrm{m}^{2} / \mathrm{s}$ ). Starting free calcium was set to $600 \mathrm{~nm}$ in both models because observed unperturbed $\Delta F / F$ values were in the same range. Note that the spatial range of maximal calcium concentration is only slightly larger in OLM cells. B, Graphing the time course of the calcium elevation at $0,0.5$, and $1 \mu \mathrm{m}$ reveals that the higher fixed buffer content in granule cell dendrites primarily slows the spread of the calcium elevation, whereas the other parameters of calcium handling work together to maintain a comparable level of calcium increase. C, Comparison of propagation velocity of the peak calcium concentration along the dendrite. This velocity is also well fit by a line with slope constrained to $2 \sqrt{D_{\text {app }} / \tau}$, as indicated by the dashed lines and fitting values on the graph.

endogenous calcium binding sites, consistent with removal of mobile $\mathrm{Cb}$ (Fig. $3 B$ ). Fourth, we found that the calcium binding ratio of WT cells during the late whole-cell recording period equals the calcium binding ratio of granule cells in $\mathrm{Cb}-\mathrm{KO}$ mice (Fig. 3C).

Our experiments were designed to characterize calcium signaling at a defined time, either early or late, to separate the mobile from the immobile buffer fraction. This design made it necessary to construct the $\kappa_{\text {dye }}$ versus $\tau_{\text {decay }}$ and inverse amplitude plots (Fig. 2) from data pooled across different cells, whereas previous studies characterized calcium signaling during the entire wholecell loading period. Thus, our estimates of $\kappa_{\text {fixed }}$ are influenced by cell-to-cell variability. However, because the $\kappa_{\text {fixed }}$ values for granule cells and OLM interneurons derived independently from the decay time constant and the inverse amplitudes agree very well, we are confident that the values closely represent the population of each cell type. More importantly, our approach of analyzing calcium handling at fixed times has the advantage that the $\kappa_{\text {fixed }}$ values are not confounded by the systematic and timedependent changes of extrusion and calcium entry that we observed in this study (see below).
Proximal dendrites of hippocampal excitatory cells display $\boldsymbol{\kappa}_{\text {endo }}$ values of 30-100 (Helmchen et al., 1996; Lee et al., 2000b; Maravall et al., 2000; Sabatini et al., 2002), which likely represent mixtures of immobile and mobile calcium buffers because the contribution of each has not been distinguished thus far. In light of these values, our estimate of pure $\kappa_{\text {fixed }}$ of $\sim 100$, i.e., without $\mathrm{Cb}$, is unexpectedly large and means that calcium signaling in granule cells, even in the absence of $\mathrm{Cb}$, is highly buffered. In this context, it is interesting to note that $\mathrm{Cb}$ expression begins relatively late during development (end of second postnatal week; Tortosa and Ferrer, 1994; Yoon et al., 2000; Müller et al., 2005), implying that young granule cells have to rely solely on fixed buffers. In contrast to granule cells, the $\kappa_{\text {fixed }}$ value of OLM interneurons (30) is unexpectedly low. This contrasting low $\kappa_{\text {fixed }}$ value contradicts the assumption that fixed calcium buffers simply comprise ubiquitous immobile intracellular proteins. Furthermore, previous studies estimating $\kappa_{\text {endo }}$ (residual mobile plus fixed calcium buffers) in other types of interneurons report large values between 70 and 220 (Kaiser et al., 2001; Goldberg et al., 2003; Rozsa et al., 2004; Aponte et al., 2008; Evstratova et al., 2011). In contrast to OLM cells, those interneurons express cal- 
A

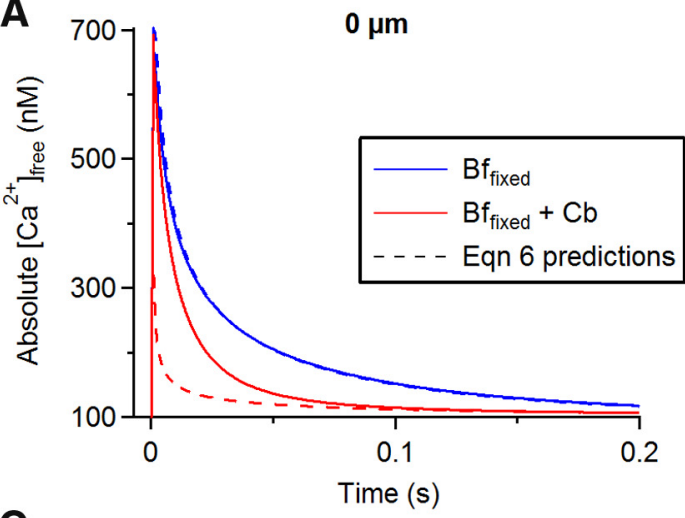

C

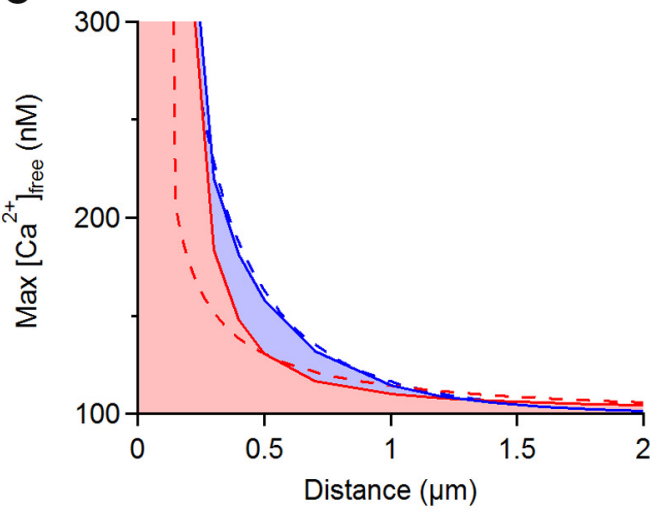

B

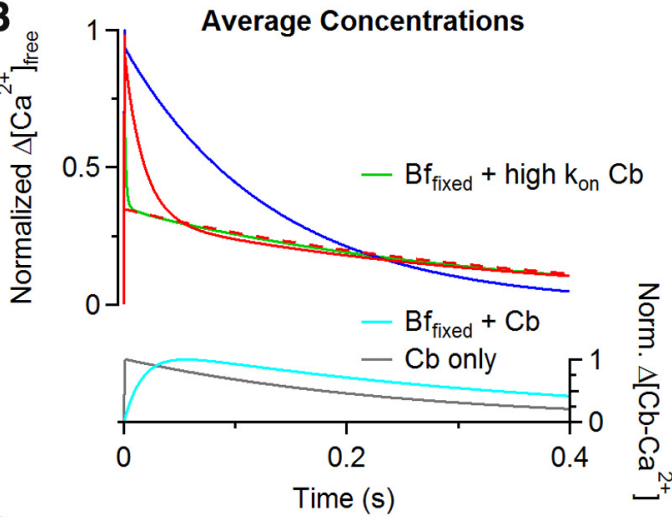

D

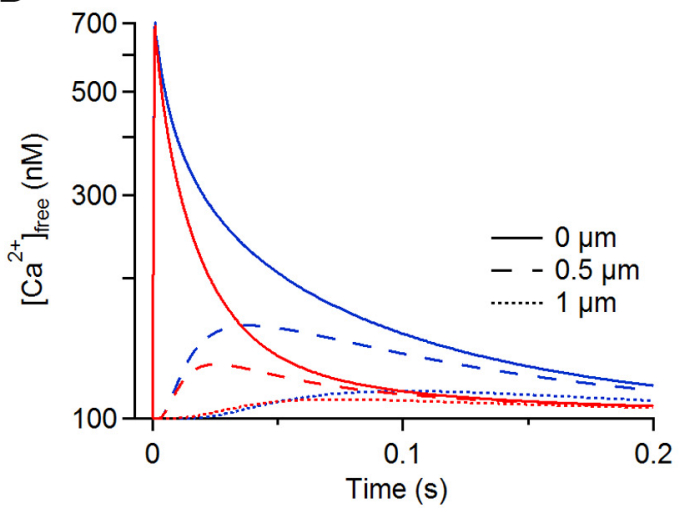

E

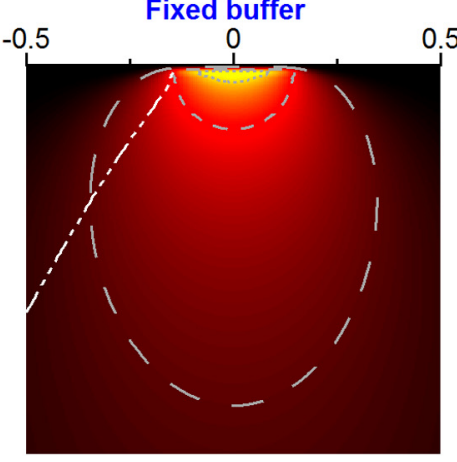

F

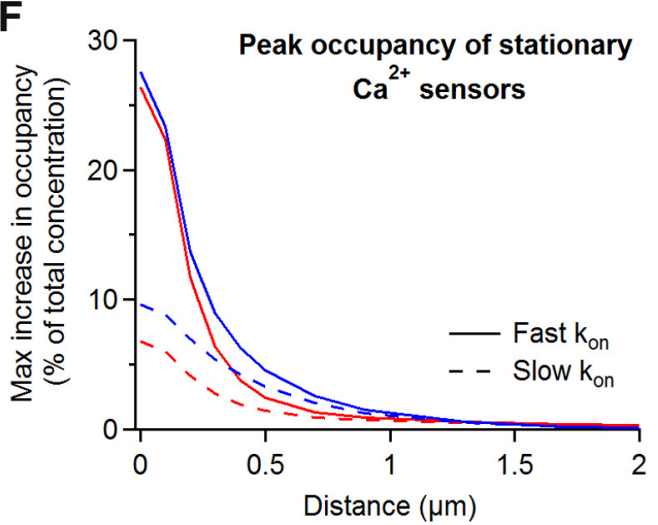

Fixed buffer $+\mathrm{Cb}$ ${ }_{1} \mu \mathrm{m}$
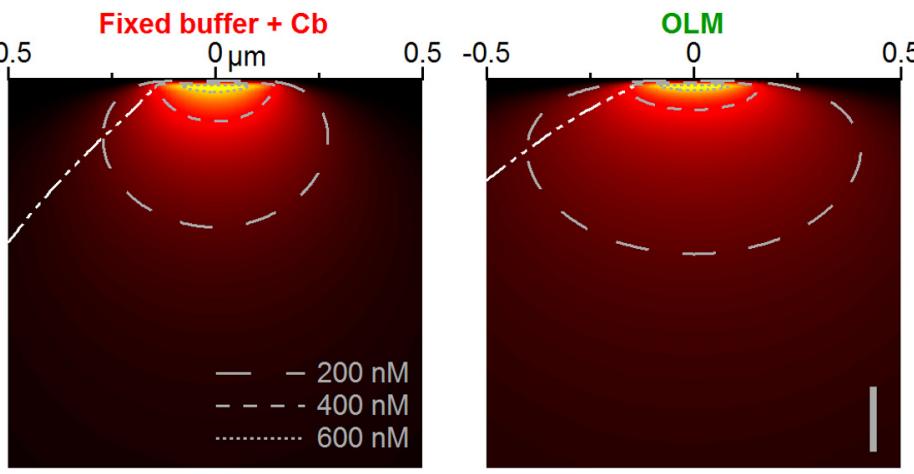

G

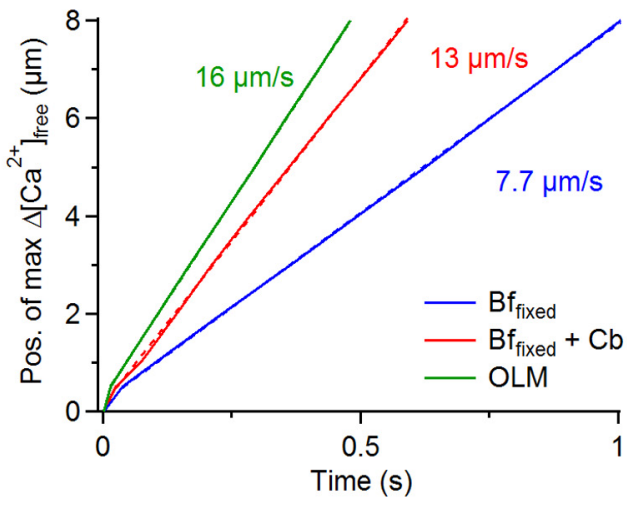

Figure 9. Cb acts as a spatial and temporal high-pass filter and leaves the peak calcium concentration at the entry site unaffected. $A$, Adding $C b$ to the background of experimentally determined fixed buffering capacity and calcium extrusion in a model of a dentate granule cell dendrite had no effect on the peak concentration of free calcium at the central entry site but strongly accelerated the decay of the calcium transient. This result deviates markedly from the prediction obtained by adding a mobile buffer to the $D_{\text {app }}$ calculation (Eq. 4) and substituting this into Equation 6. Note the close match between prediction and simulation for the fixed buffer case. In all panels, the numerical simulation results for fixed buffer ( $\mathrm{Bf}_{\text {fixed, }}$, blue) alone or fixed buffer with $\mathrm{Cb}\left(\mathrm{Bf}_{\text {fixed }}+\mathrm{Cb}\right.$, red) are illustrated with solid lines. The predictions of Equation 6 for each condition are shown with dotted lines. $\boldsymbol{B}$, The spatially averaged calcium concentration across the simulation volume normalized to the peak concentration of the $\mathrm{Bf}_{\text {fixed }}$ case is plotted over time to demonstrate the chemical binding kinetics in the system. Note the additional decay time constant of calcium in the first $50 \mathrm{~ms}$ of the $\mathrm{Bf}_{\text {fixed }}+\mathrm{Cb}$ case (red line), which occurs in parallel to the slow buildup of $\left[\mathrm{Cb}-\mathrm{Ca}^{2+}\right]$ as seen in the bottom panel (light blue line, normalized to peak concentration; at rest, $20 \mu \mathrm{m} C \mathrm{Cb}$ is bound

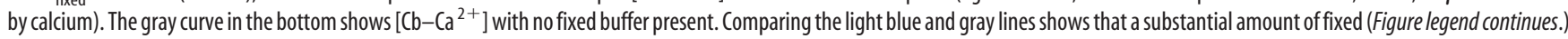


cium binding proteins, such as PV. Our results suggest that OLM cells do not compensate for the lack of calcium binding proteins with an elevated $\kappa_{\text {fixed }}$. Our low estimate of $\kappa_{\text {fixed }}$ is identical to the $\kappa_{\text {endo }}$ found in a recent study (Liao and Lien, 2009), which did not control for loss of endogenous buffers during whole-cell recording. In light of our findings, the endogenous calcium binding ratio determined by Liao and Lien (2009) is probably entirely attributable to immobile calcium buffers.

We observed a systematic time-dependent change in the fitted slopes for the $\kappa_{\text {fixed }}$ versus $\tau_{\text {decay }}$ and inverse amplitude plots (Figs. $3 B, 5 B, C$ ). This change indicated that the extrusion rate and total calcium entry substantially decreased from the early to the late recording period. This decrease was seen in both granule cells and OLM interneurons and may be viewed as "rundown" or loss of activity of ion channels and pump proteins. This recording-time-dependent rundown does not disturb our approximation of $\kappa_{\text {endo }}$ because our measures were taken at a single time point (early or late) for all cells and thus are immune to time-dependent changes. The single-compartment model predicts that the product of the amplitude of the calcium signal and the decay time constant $(A \times \tau)$ remains constant even if the amount of cellular calcium buffers (dyes or endogenous buffers) changes. Constancy of the product $A \times \tau$ has been used as an internal check for dye loading experiments to ensure that rundown of calcium entry has not obscured the loss of endogenous buffers (Helmchen et al., 1996; Lee et al., 2000b). However, if both extrusion and entry run down, $A \times \tau$ can remain constant. Indeed, the product $A \times \tau$ does not change for granule cells from

\section{$\leftarrow$}

(Figure legend continued.) buffer is needed to observe the delayed peak of the $\left[\mathrm{Cb}_{-} \mathrm{Ca}^{2+}\right]$ curve. To achieve a comparable initial free calcium concentration, we reduced the calcium entry to $8 \%$ of the regular condition. $\mathrm{C}$, The presence of $\mathrm{Cb}$ sharpens the spatial gradient of peak calcium concentrations. Because of its slow binding of calcium, $\mathrm{Cb}$ violates the singlecompartment model (rapid buffer approximation, red dashed line) and does not reduce peak calcium concentrations at distances $<300 \mathrm{~nm}$ despite strongly increasing the calcium binding ratio from 100 to $\sim 275$. The role of $\mathrm{Cb}$ in transporting calcium ions is seen as a net increase in free calcium over the fixed buffer case only at distances $>1.3 \mu \mathrm{m}$, when calcium levels have already fallen to values close to the resting concentration of $100 \mathrm{~nm}$. Note that the maximum calcium concentrations plotted for this graph occur at different time points. The physically existing gradients are even steeper and the effect of $(b$ is even more pronounced (see $\boldsymbol{D}$ and $\boldsymbol{E}$ ). D, The log plot of the calcium concentration over time at $0,0.5$, and $1 \mu \mathrm{m}$ (as in Figs. 7,8 ) reveals that the peak concentration is reached earlier peripheral to the site of entry when $\mathrm{Cb}$ is present. The peak concentration is also lower at the more distant locations, but $\mathrm{Cb}$ is too slow to influence the peak concentration at the entry site. At intermediate distances $(0.5 \mu \mathrm{m})$, the free calcium concentration is reduced as a result of a combination of buffering and increased diffusion by $\mathrm{Cb}$. At remote sites $(>1 \mu \mathrm{m})$, the early rise in free calcium concentration (30-50 ms) in the presence of $\mathrm{Cb}$ slightly exceeds the $\mathrm{Bf}_{\text {fixed }}$ case via the calcium-shuttling effect on diffusion. E, $2 \mathrm{D}$ color-coded plots of free calcium in space and time ( $x$-axis and $y$-axis, respectively) illustrate the spatiotemporal distribution of calcium in OLM cells (right; scale bar, $10 \mathrm{~ms}$ ), and dentate granule cells either with (middle) or without (left) $\mathrm{Cb}$. Cb primarily shortens the duration of calcium signals at all distances, but it only minimally reduces the peak concentration at the site of entry. Gray contour lines indicate the concentration of free calcium at each point in time and space. The straight white lines denote the time point when the local maximal calcium concentration is reached for each distance. The slopes of these lines represent the velocity of the spread of the calcium cloud. $\boldsymbol{F}$, Fast calcium sensors successfully compete with $\mathrm{Cb}$ for calcium binding. The calcium sensors are immobile and have a calcium affinity of $1 \mu \mathrm{m}$. A fast calcium sensor $\left[k_{\text {on }}\right.$ $=0.8(\mu \mathrm{m} \mathrm{ms})^{-1}$; solid lines] reaches the same peak occupancy close to the site of entry with or without $C b$ present. In contrast, the peak occupancy of a slow calcium sensor $\left[k_{\text {on }}=0.02(\mu \mathrm{M}\right.$ $\mathrm{ms})^{-1}$; dashed lines] is substantially reduced throughout space. Both sensors were added at picomolar concentrations such that they do not notably influence the free calcium concentration themselves. At rest, the occupancy of both sensors is 9\%. G, The velocities of the spread of the calcium cloud, as measured in the numerical simulations, for dentate granule cells with and without $\mathrm{Cb}$ and $\mathrm{OLM}$ cells. The addition of $\mathrm{Cb}$ to dentate granule cells makes the speed of the calcium peak similar in dentate granule and OLM dendrites. the early to the late period ( $13 \pm 1$ to $14 \pm 2 \%^{*} s, p=0.499$ ), despite a reduction of extrusion rate and total entry to $\sim 50 \%$ of the early values.

Previous calcium imaging studies in central neurons reported no alteration in the calcium binding capacity over the course of long-duration whole-cell recordings and concluded that diffusible buffers did not contribute significantly to endogenous buffering (Helmchen et al., 1996; Lee et al., 2000b; Sabatini et al., 2002; Stocca et al., 2008), contrasting with our observation that $\kappa_{\text {endo }}$ of granule cells substantially decreases over $40 \mathrm{~min}$ of whole-cell recording. A major reason for this discrepancy may be that the earlier studies directly compare time constants or amplitudes of calcium signals over the time course of the recording session. This makes it very difficult to clearly separate the impact of changing dye concentration, endogenous buffer concentration, time-dependent rundown of ion channels, and pump activity. We eliminated the confounding factors of time-dependent rundown and changing indicator concentration and specifically estimated the endogenous buffer concentration by obtaining full $\kappa_{\text {dye }}$ plots at defined time points for both the early and late recording period. In all probability, the previously recorded $\kappa_{\text {endo }}$ values represent a mixture of mobile and fixed endogenous calcium buffers. The fraction of each component may depend on the recording paradigm, the distance of the recording site from the tip of the patch pipette, and the molecular weight of the mobile buffers. Therefore, it remains difficult to assess how the previously reported $\kappa_{\text {endo }}$ values relate to $\kappa_{\text {fixed }}$ and how they would affect spatial calcium signaling. It should also be noted that, in the present study and in previous reports, millimolar amounts of ATP were routinely included in the pipette solution. ATP binds calcium and is relatively mobile because of its small size. Thus, by adding ATP, the calcium binding capacity and the observed calcium diffusion coefficient may be increased. However, the resulting free ATP concentration inside a neuron may be substantially lower, and a comparison of patch clamp recordings with and without ATP indeed indicated that ATP may not be an important confounding factor (see Materials and Methods).

Whether and how much a mobile calcium binding protein such as $\mathrm{Cb}$ increases calcium diffusion depends on the amount of fixed calcium buffers present. Equation 4 states that only when $\kappa_{\text {fixed }}>10$ does Cb increase $D_{\text {app }}$ (assuming $D_{\mathrm{Cb}}=20 \mu \mathrm{m}^{2} / \mathrm{s}$ and $\kappa_{\mathrm{Cb}}^{\text {fixed }}=175$; Schmidt et al., 2005). Thus, with $\kappa_{\text {fixed }}=100$ in granule cells, Cb strongly increases $D_{\text {app }}$ by more than sixfold.

The $D_{\text {app }}$ of calcium is a critical parameter setting the mean diffusional distance of calcium ions before they are extruded given by $\frac{2}{\sqrt{\pi}} \sqrt{D_{\text {app }} 2 \tau}$ (see Results). Substituting Equations 4 and 2

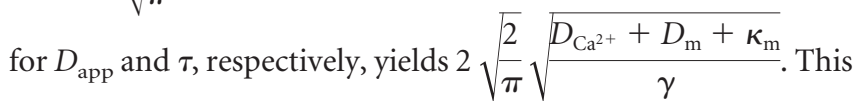
shows that the mean diffusional distance of calcium is not influenced by the concentration of fixed buffers. In contrast, adding $\mathrm{Cb}$ to granule cells substantially increases this distance from 0.6 to $\sim 2.5 \mu \mathrm{m}$. However, the above equation does not specify the resulting free calcium concentration. The fraction of free calcium concentration is reduced by the 2.7 -fold larger total $\kappa$ value, and therefore the increase in maximal free calcium concentration at more remote locations remains physiologically irrelevant in the presence of $\mathrm{Cb}(<20 \mathrm{~nm}$; compare with Fig. 9C). This situation is different for a persistent point source of calcium that causes a steady gradient of free calcium along a dendrite described by 
$\lambda=\sqrt{D_{\text {app }} \tau}=\sqrt{\frac{D_{\mathrm{Ca}^{2+}}+D_{\mathrm{m}}+\kappa_{\mathrm{m}}}{\gamma}}$ (Zador and Koch, 1994). Cb profoundly increases this length constant, approximately fourfold, but it takes $>1 \mathrm{~s}$ for the standing gradient to develop, and it is questionable whether, for example, local synaptic input could be active for so long (synaptic fatigue, cessation of presynaptic firing).

An increased $D_{\text {app }}$ can also strongly impact the propagation velocity of calcium as measured by the time needed to reach the maximum calcium concentration at a given position along the dendrite (compare Figs. 7D, 8C, $9 E, G$ ). The position of this maximum is given by $\sqrt{2} \sqrt{\frac{D t(2 t+\tau)}{\tau}}$ (for the simpler case of an instantaneous point source of calcium). It can be seen that, for $t<0.1 \times \tau[\sim 40 \mathrm{~ms} ; \tau \sim(130 \mathrm{~ms} \times 2.7)$, scaled for presence of $\mathrm{Cb}$; see Materials and Methods], this equation can be approximated by $\sqrt{2 D_{\text {app }}} \sqrt{t}$. Thus, once $\mathrm{Cb}$ has primarily reacted with calcium $(>10 \mathrm{~ms})$, it accelerates the early spread of calcium by a factor of 2.5, as shown by comparing the white dashed lines in Figure $9 E\left(\sim \sqrt{6}\right.$, attributable to a sixfold increase in $\left.D_{\text {app }}\right)$. For $t>0.1 \times \tau$ $(\sim 40 \mathrm{~ms})$, the peak of the calcium concentration moves with a constant speed given by $2 \sqrt{\frac{D_{\text {app }}}{\tau}}=2 \sqrt{\frac{\gamma\left(D_{\mathrm{Ca}}+\frac{D_{\mathrm{m}}}{\kappa_{\mathrm{m}}}\right)}{\left(1+\kappa_{\mathrm{f}}+\kappa_{\mathrm{m}}\right)^{2}}}$. In this phase, calcium removal accelerates the spread by curtailing the calcium transient and thereby shortening the time to maximum. Because $\mathrm{Cb}$ also prolongs $\tau$, it increases this late propagation velocity less effectively, $\sim 1$.6-fold. Note that the latter equation also states that only for a substantial $\kappa_{\text {fixed }}(>55)$ is $\mathrm{Cb}$ able to speed up this long-range aspect of calcium signaling.

From the discussion above, it is clear that the low fixed buffer background of OLM cells prevents any additionally expressed calcium binding protein with mobility similar to $\mathrm{Cb}$ from appreciably increasing $D_{\text {app }}$ or speeding up calcium signaling. Furthermore, with a given extrusion rate, OLM cells can change their calcium signaling only by regulating the concentration of fixed calcium buffer, but this affects only the temporal and not the spatial aspect of calcium diffusion because the product $D_{\text {app }} \times \tau$ is independent of immobile buffers (see Results).

Importantly, the pronounced fixed buffering in granule cells is key not only to enabling $\mathrm{Cb}$ to increase $D_{\text {app }}$ and accelerate calcium spread but also to exposing the slow calcium association rate of $\mathrm{Cb}$ : in the absence of fixed buffer, $\left[\mathrm{Cb}-\mathrm{Ca}^{2+}\right]$ peaks within a fraction of a millisecond (Fig. $9 B$, bottom) because even initial binding of calcium by $\mathrm{Cb}$ is sufficient to rapidly reduce the free calcium concentration into a range in which it is in equilibrium with $\mathrm{Cb}$. In fact, $\kappa_{\text {fixed }}$ must exceed 50 to delay the peak of [ $\mathrm{Cb}-$ $\left.\mathrm{Ca}^{2+}\right]$ by a physiologically relevant period of $>10 \mathrm{~ms}$. In other words, $\kappa_{\text {fixed }}$ must exceed 50 for $\mathrm{Cb}$ to leave the initial peak calcium concentration unaffected and favor the activation of fast calcium sensors close to the source. Mature granule cells and other neurons are able to upregulate and downregulate intracellular $\mathrm{Cb}$ level in reaction to pathological conditions (Iacopino and Christakos, 1990; Mattson et al., 1995; Maglóczky et al., 1997; Selke et al., 2006; Martinian et al., 2012), which gives them, within the context of pronounced fixed buffering, access to a large repertoire of calcium signaling regimens.

\section{References}

Airaksinen MS, Eilers J, Garaschuk O, Thoenen H, Konnerth A, Meyer M (1997) Ataxia and altered dendritic calcium signaling in mice carrying a targeted null mutation of the calbindin D28k gene. Proc Natl Acad Sci U S A 94:1488-1493. CrossRef Medline

al-Baldawi NF, Abercrombie RF (1995) Calcium diffusion coefficient in Myxicola axoplasm. Cell calcium 17:422-430. CrossRef Medline

Allbritton NL, Meyer T, Stryer L (1992) Range of messenger action of calcium ion and inositol 1,4,5-trisphosphate. Science 258:1812-1815. CrossRef Medline

Aponte Y, Bischofberger J, Jonas P (2008) Efficient $\mathrm{Ca}^{2+}$ buffering in fastspiking basket cells of rat hippocampus. J Physiol 586:2061-2075. CrossRef Medline

Augustine GJ, Santamaria F, Tanaka K (2003) Local calcium signaling in neurons. Neuron 40:331-346. CrossRef Medline

Berggård T, Miron S, Onnerfjord P, Thulin E, Akerfeldt KS, Enghild JJ, Akke M, Linse S (2002) Calbindin D28k exhibits properties characteristic of a $\mathrm{Ca}^{2+}$ sensor. J Biol Chem 277:16662-16672. CrossRef Medline

Crank J (1975) The mathematics of diffusion, Ed 2. Oxford, UK: Oxford UP.

Evstratova A, Chamberland S, Topolnik L (2011) Cell type-specific and activity-dependent dynamics of action potential-evoked $\mathrm{Ca}^{2+}$ signals in dendrites of hippocampal inhibitory interneurons. J Physiol 589:19571977. CrossRef Medline

Faas GC, Raghavachari S, Lisman JE, Mody I (2011) Calmodulin as a direct detector of $\mathrm{Ca}^{2+}$ signals. Nat Neurosci 14:301-304. CrossRef Medline

Gabso M, Neher E, Spira ME (1997) Low mobility of the $\mathrm{Ca}^{2+}$ buffers in axons of cultured Aplysia neurons. Neuron 18:473-481. CrossRef Medline

Goldberg JH, Tamas G, Aronov D, Yuste R (2003) Calcium microdomains in aspiny dendrites. Neuron 40:807-821. CrossRef Medline

Helmchen F, Imoto K, Sakmann B (1996) $\mathrm{Ca}^{2+}$ buffering and action potential-evoked $\mathrm{Ca}^{2+}$ signaling in dendrites of pyramidal neurons. Biophys J 70:1069-1081. CrossRef Medline

Hodgkin AL, Keynes RD (1957) Movements of labelled calcium in squid giant axons. J Physiol 138:253-281. Medline

Iacopino AM, Christakos S (1990) Specific reduction of calcium-binding protein (28-kilodalton calbindin-D) gene expression in aging and neurodegenerative diseases. Proc Natl Acad Sci U S A 87:4078-4082. CrossRef Medline

Jackson MB, Redman SJ (2003) Calcium dynamics, buffering, and buffer saturation in the boutons of dentate granule-cell axons in the hilus. J Neurosci 23:1612-1621. Medline

Junge W, McLaughlin S (1987) The role of fixed and mobile buffers in the kinetics of proton movement. Biochim Biophys Acta 890:1-5. CrossRef Medline

Kaiser KM, Zilberter Y, Sakmann B (2001) Back-propagating action potentials mediate calcium signalling in dendrites of bitufted interneurons in layer $2 / 3$ of rat somatosensory cortex. J Physiol 535:17-31. CrossRef Medline

Kasai H, Petersen OH (1994) Spatial dynamics of second messengers: IP3 and cAMP as long-range and associative messengers. Trends Neurosci 17:95-101. CrossRef Medline

Kosaka T, Katsumaru H, Hama K, Wu JY, Heizmann CW (1987) GABAergic neurons containing the $\mathrm{Ca}^{2+}$-binding protein parvalbumin in the rat hippocampus and dentate gyrus. Brain Res 419:119-130. CrossRef Medline

Lee SH, Schwaller B, Neher E (2000a) Kinetics of $\mathrm{Ca}^{2+}$ binding to parvalbumin in bovine chromaffin cells: implications for $\left[\mathrm{Ca}^{2+}\right]$ transients of neuronal dendrites. J Physiol 525:419-432. Medline

Lee SH, Rosenmund C, Schwaller B, Neher E (2000b) Differences in $\mathrm{Ca}^{2+}$ buffering properties between excitatory and inhibitory hippocampal neurons from the rat. J Physiol 525:405-418. Medline

Liao CW, Lien CC (2009) Estimating intracellular $\mathrm{Ca}^{2+}$ concentrations and buffering in a dendritic inhibitory hippocampal interneuron. Neuroscience 164:1701-1711. CrossRef Medline

Maccaferri G, McBain CJ (1996) The hyperpolarization-activated current (Ih) and its contribution to pacemaker activity in rat CA1 hippocampal stratum oriens-alveus interneurones. J Physiol 497:119-130. Medline

Maccaferri G, Roberts JD, Szucs P, Cottingham CA, Somogyi P (2000) Cell surface domain specific postsynaptic currents evoked by identified GABAergic neurones in rat hippocampus in vitro. J Physiol 524:91-116. Medline

Maglóczky Z, Halász P, Vajda J, Czirják S, Freund TF (1997) Loss of 
Calbindin-D28K immunoreactivity from dentate granule cells in human temporal lobe epilepsy. Neuroscience 76:377-385. CrossRef Medline

Maravall M, Mainen ZF, Sabatini BL, Svoboda K (2000) Estimating intracellular calcium concentrations and buffering without wavelength ratioing. Biophys J 78:2655-2667. CrossRef Medline

Markram H, Roth A, Helmchen F (1998) Competitive calcium binding: implications for dendritic calcium signaling. J Comput Neurosci 5:331-348. CrossRef Medline

Martinian L, Catarino CB, Thompson P, Sisodiya SM, Thom M (2012) Calbindin D28K expression in relation to granule cell dispersion, mossy fibre sprouting and memory impairment in hippocampal sclerosis: a surgical and post mortem series. Epilepsy Res 98:14-24. CrossRef Medline

Mattson MP, Cheng B, Baldwin SA, Smith-Swintosky VL, Keller J, Geddes JW, Scheff SW, Christakos S (1995) Brain injury and tumor necrosis factors induce calbindin D-28k in astrocytes: evidence for a cytoprotective response. J Neurosci Res 42:357-370. CrossRef Medline

Müller A, Kukley M, Stausberg P, Beck H, Müller W, Dietrich D (2005) Endogenous $\mathrm{Ca}^{2+}$ buffer concentration and $\mathrm{Ca}^{2+}$ microdomains in hippocampal neurons. J Neurosci 25:558-565. CrossRef Medline

Nägerl UV, Novo D, Mody I, Vergara JL (2000) Binding kinetics of calbindin- $\mathrm{D}(28 \mathrm{k})$ determined by flash photolysis of caged $\mathrm{Ca}^{2+}$. Biophys J 79:3009-3018. CrossRef Medline

Neher E (1998) Usefulness and limitations of linear approximations to the understanding of $\mathrm{Ca}^{2+}$ signals. Cell Calcium 24:345-357. CrossRef Medline

Neher E, Augustine GJ (1992) Calcium gradients and buffers in bovine chromaffin cells. J Physiol 450:273-301. Medline

Nowycky MC, Pinter MJ (1993) Time courses of calcium and calciumbound buffers following calcium influx in a model cell. Biophys J 64:7791. CrossRef Medline

Pusch M, Neher E (1988) Rates of diffusional exchange between small cells and a measuring patch pipette. Pflugers Arch 411:204-211. CrossRef Medline

Rozsa B, Zelles T, Vizi ES, Lendvai B (2004) Distance-dependent scaling of calcium transients evoked by backpropagating spikes and synaptic activity in dendrites of hippocampal interneurons. J Neurosci 24:661-670. CrossRef Medline

Sabatini BL, Maravall M, Svoboda K (2001) $\mathrm{Ca}^{2+}$ signaling in dendritic spines. Curr Opin Neurobiol 11:349-356. CrossRef Medline
Sabatini BL, Oertner TG, Svoboda K (2002) The life cycle of $\mathrm{Ca}^{2+}$ ions in dendritic spines. Neuron 33:439-452. CrossRef Medline

Sala F, Hernández-Cruz A (1990) Calcium diffusion modeling in a spherical neuron. Relevance of buffering properties. Biophys J 57:313-324. CrossRef Medline

Schmidt H, Schwaller B, Eilers J (2005) Calbindin D28k targets myoinositol monophosphatase in spines and dendrites of cerebellar Purkinje neurons. Proc Natl Acad Sci U S A 102:5850-5855. CrossRef Medline

Schwaller B (2010) Cytosolic $\mathrm{Ca}^{2+}$ buffers. Cold Spring Harb Perspect Biol 2:a004051. CrossRef Medline

Selke K, Müller A, Kukley M, Schramm J, Dietrich D (2006) Firing pattern and calbindin-D28k content of human epileptic granule cells. Brain Res 1120:191-201. CrossRef Medline

Sheng M, Hoogenraad CC (2007) The postsynaptic architecture of excitatory synapses: a more quantitative view. Annu Rev Biochem 76:823-847. CrossRef Medline

Sinha SR, Wu LG, Saggau P (1997) Presynaptic calcium dynamics and transmitter release evoked by single action potentials at mammalian central synapses. Biophys J 72:637-651. CrossRef Medline

Stocca G, Schmidt-Hieber C, Bischofberger J (2008) Differential dendritic $\mathrm{Ca}^{2+}$ signalling in young and mature hippocampal granule cells. J Physiol 586:3795-3811. CrossRef Medline

Tortosa A, Ferrer I (1994) Poor correlation between delayed neuronal death induced by transient forebrain ischemia, and immunoreactivity for parvalbumin and calbindin D-28k in developing gerbil hippocampus. Acta Neuropathol 88:67-74. CrossRef Medline

Wagner J, Keizer J (1994) Effects of rapid buffers on $\mathrm{Ca}^{2+}$ diffusion and $\mathrm{Ca}^{2+}$ oscillations. Biophys J 67:447-456. CrossRef Medline

Xu T, Naraghi M, Kang H, Neher E (1997) Kinetic studies of $\mathrm{Ca}^{2+}$ binding and $\mathrm{Ca}^{2+}$ clearance in the cytosol of adrenal chromaffin cells. Biophys J 73:532-545. CrossRef Medline

Yoon SP, Chung YY, Chang IY, Kim JJ, Moon JS, Kim HS (2000) Postnatal development of parvalbumin and calbindin D-28k immunoreactivities in the canine hippocampus. J Chem Neuroanat 19:143-154. CrossRef Medline

Zador A, Koch C (1994) Linearized models of calcium dynamics: formal equivalence to the cable equation. J Neurosci 14:4705-4715. Medline

Zhou Z, Neher E (1993) Mobile and immobile calcium buffers in bovine adrenal chromaffin cells. J Physiol 469:245-273. Medline 